\title{
Article
}

\section{Uncertainty based design floods}

\author{
Radu Drobot 1,* , Aurelian Florentin Draghia ${ }^{2}$, Daniel Ciuiu ${ }^{3,4}$ and Romică Trandafir ${ }^{3}$ \\ 1 Technical University of Civil Engineering, Bucharest, Department of Hydrotechnical Engineering; \\ radu.drobot@utcb.ro \\ 2 Roua Soft SRL; draghia_aurelian@yahoo.com \\ 3 Technical University of Civil Engineering, Bucharest, Department of Mathematics; daniel.ciuiu@utcb.ro, \\ romica.trandafir@gmail.com \\ 4 Centre of Macroeconomic Modelling, National Institute of Economic Research "Costin C. Kiritescu", \\ Romanian Academy; daniel.ciuiu@utcb.ro \\ * Correspondence: radu.drobot@utcb.ro
}

\begin{abstract}
Many statistical distributions approximate well the frequent values of the maximum discharges, but have a very large spread for medium or rare probabilities of exceedance. This scattering defines a range of uncertainty of maximum discharges outside the measured values. Based on the upper $(\mathrm{U})$ and lower $(\mathrm{L})$ values of the uncertainty interval, a maximum discharge flood (MDF) and a maximum volume flood (MVF) are defined for each probability of exceedance. This approach is in agreement with the bivariate analysis, the contour lines for a certain probability of exceedance putting into evidence an infinity of couples (maximum discharge, flood volume). If the most critical combinations are selected, the MDF and MVF are derived. Apart from maximum discharge and flood volume, the shape of the design flood, characterized by the time to peak and the total duration, is also important. The easiest way to obtain the design flood is to use an analytical curve that passes through the characteristic points of the flood. Another possibility, which was largely developed in this paper, is to normalize the floods, then to define clusters of floods with similar shapes, and to obtain an average dimensionless flood for each class. Finally, a family of design floods with different shapes, but characterized by the same parameters for each probability of exceedance, are derived. The use of these floods in the design or operation of hydrotechnical works or in the delineation of flooded areas is presented at the end.
\end{abstract}

Keywords: BM; POT; design flood; uncertainty interval; flood parameters; compactness coefficient; flood shape; aleatory and epistemic uncertainty

\section{Introduction}

The design flood represents the maximum flood that a hydraulic structure can safely pass [1] or that can guarantee the safety of hydraulic structures [2,3]. The magnitude of the design flood is usually associated with the probability of exceedance of the maximum discharge [4]. The probability of exceedance represents the complementary value of the security degree of the objective to be protected.

In the current practice, the flood hydrograph for the probability of exceedance $P \%$ is constructed considering the maximum discharge $Q_{P \%}$ and the output volume of a hydrological model, previously calibrated [3].

The correct estimation of the design flood is necessary for proper planning, design and operation of major hydraulic structures (dams and reservoirs, dikes, diversions) or structures associated with water (bridges, culverts, drainage systems, pumping stations), as well as for the delineation of the flooded areas and flood risk management.

There are different approaches to obtain the design flood [5-7] among which one can cite: 
- Empirical formulae, which derive the peak discharge as a function of catchment size and climatic catchment characteristics.

- Envelope curves of observed floods

- Methods based on the frequency analyses of observed floods. The analysis can be at-site or at regional level.

- Joint peak-volume design flood methodology, which derives the exceedance probability of the design flood volume given a design peak discharge based on a regional approach.

- Rainfall-based methods: a) The design event-based models consider that the probability of exceedance of the design flood is equal to the probability of exceedance of the input rainfall, (assumption which except for small catchments is not valid); b) In the joint probability approach, a deterministic rainfall-runoff model receives probability-distributed inputs to obtain probability-distributed outputs; c) The continuous simulation uses the registered or generated rainfall for a long period to compute the flood hydrographs, subjected then to statistical processing.

In the past and even quite recently, only the maximum discharge corresponding to different probabilities of exceedance was considered to be the main parameter of the design flood [5, 8-12]. This approach is leading in steady state hydraulic simulation to the worst extension of the flooded areas. The result is an over-evaluation of the flood extent, since the flood attenuation in the floodplain is not taking into account the storage in the depression areas and the corresponding decrease of the maximum discharge in the downstream sections.

The volume of the design flood is also of maximum interest especially in the case of large reservoirs, which storing partially the flood attenuate the peak discharge, as it is the case of the Three Gorges Reservoir [13].

In bivariate flood frequency analysis both the maximum discharges and the corresponding flood volume are considered [14-22]. This approach is necessary if the purpose is to derive the storage for flood control of the reservoirs and the spillways characteristics. The maximum discharges and the flood volumes are not independent variables, and can be studied using either the bivariate frequency analysis [23], or copulas which overcome the drawbacks of the bivariate distributions [14, 24].

Chuntian et al [25] considered not only the peak discharge and the flood volume, but also the peak time. Other authors [14, 26, 27] characterize a flood by peak, volume, duration, which are correlated random variables.

Mediero et al. [3] generated a set of synthetic hydrographs that preserved the statistical characteristics of the observed peaks, volumes and durations, while the hydrograph shape was defined by two variables: the time of the peak and the location of the hydrograph centroid.

Brunner et al [17] used for the characterization of a flood event the following parameters: peak discharge, time to peak, duration and flood volume. However, for the bivariate return periods they used only two design variables, peak discharge and flood volume; although the flood duration was mentioned as a potential variable, a window of 72 hours, which was kept constant, was considered for the flood volume estimation.

Brunner et al [28] obtained the Synthetic Design Hydrograph based on peak magnitude and flood volume, using frequency analysis, and a selected probability density function to model the shape of a normalized registered hydrograph. 
Other authors included under the name of loading system variables the following characteristics describing the flow: peak discharge, flood hydrograph shape and duration, sediment transport rate, volume and concentration and rate of driftwood transport [29, 30].

In the present paper the synthetic flood, which represents a statistical footprint of a river location, is characterized by 4 main parameters [31, 32]:

- $Q_{P \%}^{\max }$ - maximum discharges corresponding to the probability of exceedance $\mathrm{P} \%$

- $T_{p}$ - the time to peak of the flood hydrograph

- $\quad D$ - total duration of the flood hydrograph

- $\quad \gamma$ - compactness coefficient, defined as follows:

$$
\gamma=\frac{W}{Q_{P \%}^{\max } D}
$$

where $W$ is the flood volume. The parameters $T_{p}, D, \gamma$ are computed as the average values of the 4-5 most significant registered floods ranked according to the maximum discharge [31].

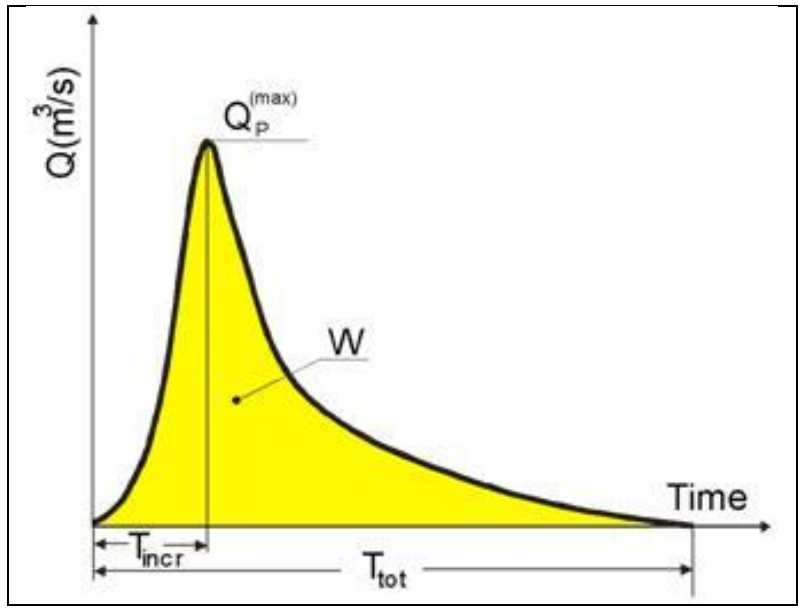

Figure 1. Parameters of the synthetic floods

In the statistical processing of the hydrological data, the complete data series is rarely used. Two methods are employed to select data of interest from the complete series [9, 33-37]:

- Annual maximum series or BM (Block maxima), obtaining the extreme value series; in this case, the annual maximum discharges is the data to be processed [5];

- Partial-duration series or POT (Peak Over Threshold), all events which exceed a pre-defined value are included in the analysis [5, 38-41].

Prior to any statistical analysis, the hydrological data have to be checked for mutual independence and identical distribution, the homogeneity and the lack of trend of the sample data. The stationarity of data, although in most of the cases implicitly supposed, is questionable due to land cover and land use changes or of climate change [42]. Statistical tests like Wald-Wolfowitz, Turning point, Mann-Whitney- Wilcoxon and Mann-Kendall were used if the basic statistical assumptions are fulfilled [43-45].

The empirical distribution of the registered data is fit by different theoretical distributions [ 5 , $34,46-48]$. 
The most commonly used distributions in hydrology can be divided into four groups [37]: the normal family (normal, log-normal, log-normal type 3), the general extreme-value (GEV) family (GEV, Gumbel, log-Gumbel, Weibull), the Pearson type 3 family (Pearson type 3, log-Pearson type 3), and the generalized Pareto distribution.

According to the selection procedure, the following distributions are preferred [49]:

a) for annual maximum series (BM): Generalized Extreme Values (GEV), Pearson 3, LogPearson3 (LP3), Gamma2, Generalized Gamma, Lognormal distribution etc.

b) for partial-duration series (POT): Generalized Pareto Distribution (GPD), Weibull, LogPearson3, Gamma2, Generalized Gamma distribution etc.

Following a comparison of different statistical distributions, one of them is selected and is considered to be adequate for a country or a region. Thus, in the United States, comparing Lognormal, Gamma, Gumbel, Log-Gumbel, Hazen and Log-Pearson3 (LP3) the recommended distribution for flood statistical analyses is LP3 [5]. Australia and Slovenia also opted for LP3 distribution, UK prefers GEV and Generalized logistics, while China uses Lognormal distribution [41, 48]. Pearson III distribution was found to be the best distribution for the extrapolation of the regional curves in Danube basin [32]. LN distribution and LP3 distribution were used for the AM analyses on the Danube River [50, 51].

If more distributions are analysed, the most suitable distribution is selected using goodness-of-fit tests, like Kolmogorov-Smirnov, Anderson-Darling or Chi-Squared tests [45, 52]. Other authors [27, 42] utilized the root mean square error, Akaike information criterion and Bayesian information criteria to select the most appropriate statistical model.

The true value of the statistical estimates is expected to lie within a confidence interval, whose size depends on the confidence level $\beta$ of the test [34].

The confidence level is expressed as $\beta=1-\alpha$, where $\alpha$ is the significance level and represents the probability of incorrectly (type I error) rejecting the null hypothesis when it is true [53]. Usually, $\beta$ is chosen to be $95 \%$. The confidence interval of an estimate indicates the uncertainty associated with the mean of the estimated value. The upper and lower limits of the confidence interval are the confidence limits, representing the margin of error around the estimated value.

The best distribution to fit the empirical data is however unknown [6] or could even change in time as a consequence of aleatory uncertainty, due to the time variability and the length of the maximum discharge's series $[52,54]$. Out of this, the registered data are subjected to epistemic uncertainty due to incomplete knowledge of the hydrological system [54-56]. The uncertainty is also present as a result of climate change scenarios [57]. Due to aleatory and epistemic uncertainty, the statistical estimates belong to an uncertainty interval, which is not similar to the confidence interval. The former depends on the spreading of the analysed statistical distributions, while the latter is associated to a given distribution.

This paper is organized as follows: Section 2 presents the Method used in this study; Section 3 provides 2 Case studies; Section 4 contains Discussions, and Section 5 Conclusions.

\section{Materials and Methods}

For the beginning, two statistical variables were separately processed:

- Maximum annual discharges (Block Maxima approach); 
- Flood volumes, selecting those floods whose discharges exceed a specified threshold value (Peak Over Threshold approach).

Then, the compactness coefficient, the shape and the flood duration of the design flood were derived.

\subsection{Maximum annual discharges}

For the annual maximum discharges, first the aleatory and then the epistemic uncertainty was investigated.

The aleatory uncertainty is highlighted by analysing time series of different lengths of the registered or generated maximum discharges. The set of registered maximum annual discharges was split into two series: the first 30 values were statistically processed and then new values were added followed by new statistical processing. In each case, the graphical representations were plotted on the normal probability paper, allowing a better visualization of the cumulative distribution function especially for small probabilities of exceedance. It was noticed that for the same value of the probability of exceedance $P \%$ the maximum discharges $Q_{p \%}^{\max }$ increase during wet periods, while after a dry period the same characteristics decrease, putting into evidence the aleatory uncertainty. The tendency of dry years and wet years to cluster together into longer dry and wet periods is known as the Hurst phenomenon [58].

A similar approach was used for the generated values of maximum discharges. Based on the sample data of maximum annual discharges, a set of 1000 values following the log Pearson 3 distribution and keeping the same statistical parameters was randomly generated. The discharges corresponding to different probabilities of exceedance were computed for successive series of generated values, by increasing step by step the number of processed discharges from 80 to 500 . One noticed that the cumulative distribution curves cover a quite large interval of values for medium and rare probabilities of exceedance, putting into evidence the aleatory uncertainty. Thus, for the probability of exceedance $0.1 \%$ the difference between the maximum and the minimum theoretical discharge is about $10 \%$. The aleatory uncertainty interval decreases with the increase of the probability of exceedance, being minimum in the central part of the distribution.

To investigate the epistemic uncertainty, using EasyFit software, a number of about 60 statistical distributions were analysed and then ordered according to Kolmogorov-Smirnov, Anderson-Darling and Chi-Squared tests. Different probability distributions fit well the empirical values, but the extrapolation outside the domain of measurements leads to a large spreading of the estimates as signalled by many authors $[47,48,52,55,59]$.

During statistical processing, it was found that minimum 8-10 ranked distributions should be kept to define the lower and the upper limits of the epistemic uncertainty interval. That means that, for a given probability of exceedance $P \%$, the peak discharge $Q_{P \%}^{\max }$ belongs to an interval denoted by $\left(Q_{L}^{\max }, Q_{U}^{\max }\right)_{P \%}$ where the symbols $L$ and $U$ refers to the lower and the upper limit respectively of the uncertainty interval. Consequently, $Q_{P \%}^{\max }$ is not a unique value as usually accepted, but it has an infinite number of values for the same probability of exceedance $P \%$.

To avoid the arbitrary selection of the number of retained distributions, one proceeds as follows:

- The discharges $Q_{0.1 \%}^{\max } \quad$ computed with the analysed statistical distributions for the probability of exceedance $0.1 \%$ is statistically processed. 
- The lower and upper values of the interval of epistemic uncertainty, $\left(Q_{L}^{\max }\right)_{0.1 \%}$ and $\left(Q_{U}^{\max }\right)_{0.1 \%}$ respectively, are chosen according to a pre-defined percentage difference between these limits. For example, the difference between the selected upper and the lower value should not exceed $20 \%$ in order to avoid a large interval of uncertainty:

$$
\frac{\left(Q_{U}^{\max }\right)_{0.1 \%}-\left(Q_{L}^{\max }\right)_{0.1 \%}}{\left.Q_{U}^{\max }\right)_{0.1 \%}} \leq 0.20
$$

- The distributions inside, but close to the interval limits $\left(Q_{L}^{\max }, Q_{U}^{\max }\right)_{P \%}$ are then chosen as the lower and upper margins of the uncertainty interval.

\subsection{Flood volumes}

As previously mentioned, the partial series of the floods' volume is processed using a POT approach. There are different recommendations concerning the selection of the threshold: to be chosen low enough that at least one event in each year is included [9], to be equal with $85 \%$ of all daily discharges, to be close to long-term mean discharge or to include in average 4 maximum values per year [50]. Another possibility is to choose the threshold equal with the bankfull discharge, when the floodplain begins to be flooded. The bankfull discharge corresponds to a sharp change in the slope of the rating curve [60]. Finally, in case of a dam regulating the river flow, the threshold can be considered equal with the discharge capacity of the bottom gates of the dam.

In this paper, the threshold is chosen in such a way the total number $n$ of selected floods is equal with the number $N$ of the years with daily or sub-daily discharges. Thus, the empirical exceedance probability associated to each measured value can be interpreted as an annual probability [9].

If $n \neq N$, the average duration of the sampling interval $d$ is less than or greater than one year if more or fewer floods respectively than the number of years are selected. The theoretical probabilities of exceedance $P_{d}=P(d)$ corresponding to the maximum discharges over a period $d$ other than the year must be converted into annual probabilities of exceedance $P_{a}=P_{1}=P(1)$, which correspond to the same maximum discharges (Figure 2).

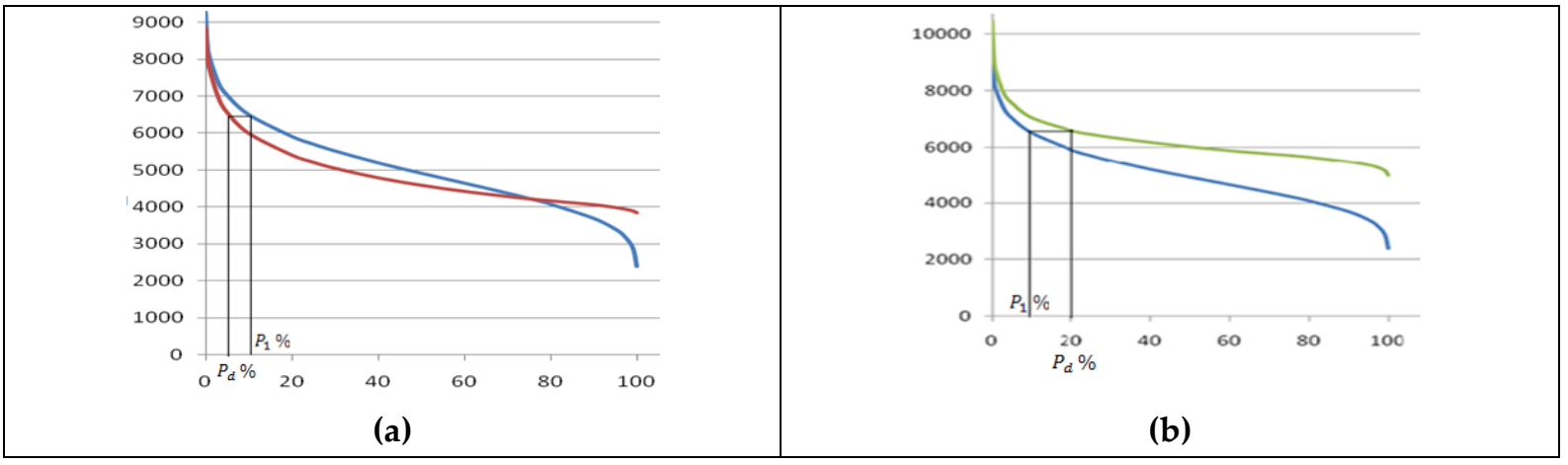

Legend: $P_{a}=$ blue line; $P_{d}$ for $n>N=$ red line; $P_{d}$ for $n<N=$ green line.

Figure 2. The relationship between the probability of exceedance $P_{d} \%$ for the sampling interval $d$ and the annual probability of exceedance $P_{1} \%$ : (a) $n>N$; (b) $n<N$.

If we denote by $F_{1}^{c}$ the annual probability of exceedance (where the index $c$ indicates the complementary function of the cumulative distribution function), respectively by $F_{d}^{c}$ the probability of exceedance corresponding to an interval $d$ different from one year, one can write: 


$$
P_{d}=F_{d}^{c}(Q)
$$

whence it results:

$$
Q=\left(F_{d}^{c}\right)^{-1}\left(P_{d}\right),
$$

Therefore, the annual probability of exceedance corresponding to the same flow rate $Q$ is:

$$
P_{1}=F_{1}^{c}(Q)=F_{1}^{c}\left[\left(F_{d}^{c}\right)^{-1}\left(P_{d}\right)\right],
$$

A similar relationship is obtained if working with the cumulative distribution function (the probability of not exceedance) instead of the exceedance probability:

$$
P_{1}=F_{1}(Q)=F_{1}\left[F_{d}^{-1}\left(P_{d}\right)\right],
$$

However, the calculation of the annual probability of exceedance in this way encounters some difficulties, because many of the usual distributions do not admit the inverse; of course, numerical inversion can be used if necessary.

An approximate solution can be obtained relatively easily, starting from the relation [34]:

$$
P_{N}=1-\left(1-P_{1}\right)^{N},
$$

where: $P_{1}$ is the annual probability of exceedance of the discharge $Q_{P \%}^{\max }$, and $P_{N}$ is the probability of exceedance of the same event for a period of $\mathrm{N}$ years.

Suppose that in $\mathrm{N}$ years with available data, a number of $M$ floods above a certain threshold were selected, where $M$ is greater than the number of years $(M>N)$. In this case, the probability of exceedance of the same event for a period of $M$ intervals of average duration $d=N / m$ (years) is:

$$
P_{M}=1-\left(1-P_{d}\right)^{M},
$$

As shown before, the probability of exceedance $P_{d}$ must be put in correspondence with the annual probability of exceedance $P=P_{1}$ for the same calculated discharge, where $d$ is the size of the average sampling interval expressed in years. Let be:

$$
\begin{aligned}
& Q_{N}=Q\left(P_{N}\right) \\
& Q_{M}=Q\left(P_{M}\right),
\end{aligned}
$$

Equating the values of the two discharges is obtained:

$$
Q\left(P_{N}\right)=Q\left(P_{M}\right)
$$

Applying the inverse function results:

$$
Q^{-1} Q\left(P_{N}\right)=Q^{-1} Q\left(P_{M}\right),
$$

or:

$$
P_{N}=P_{M},
$$

It follows from here:

$$
1-\left(1-P_{1}\right)^{N}=1-\left(1-P_{d}\right)^{M},
$$

The previous relation allows the calculation of the exceedance probability corresponding to the new average time interval $d=N / M$ years as a function of the annual probability of exceedance: 


$$
P_{d=N / M}=1-\left(1-P_{1}\right)^{\frac{N}{M}}
$$

where $P_{1}$ is the annual probability of exceedance (corresponding to a period of 1 year), and $P_{d=N / M}$ is the probability of exceedance of the new interval.

Let be for example $N=85$ years and $M=130$ selected floods. According to the above formula, to obtain the discharge with an annual probability of exceedance $1 \%$, the discharge corresponding to the probability of exceedance $0.65 \%$ based on the 130 selected values must be calculated. Thus, if $M>N$, results $P=P_{1}>P_{d}$.

If the number of $m$ selected floods is less than the number of years $N$ (i. e. $m<N$ ), the relation for the calculation of the exceedance probability corresponding to a time interval $d=N / m$ years is similar to previous one, but the average duration is now $d=N / m$ :

$$
P_{d=N / m}=1-\left(1-P_{1}\right)^{N / m}
$$

where $P_{1}$ is the annual probability of exceedance (over a time interval of 1 year), and $P_{d=N / m}$ is the probability of exceedance of the new average time interval, greater than one year. Let for example consider $\mathrm{N}=85$ years and $\mathrm{m}=48$ floods selected. To obtain the discharge with an annual probability of exceedance $1 \%$, the discharge corresponding to the probability of exceedance $1.76 \%$ based on 48 selected values must be calculated. If $m<N$, then $P=P_{1}<P_{d}$.

The previous relationships allow the transformation of probabilities $P_{d}$ into annual probabilities of exceedance. However, these additional computations are not necessary if the number of selected floods is equal to the number of years with measured values.

Considering a threshold discharge $Q_{t h r 1}$, all floods whose discharges exceeds this threshold are selected. The excess discharges are assumed to be independent with an arbitrary distribution [38]. However, the fulfilment of these basic assumptions can be checked.

In a certain year 2-3 floods can be selected, while in dry years no flood is retained for future analysis. For the selected floods, a second threshold $Q_{t h r 2}=a Q_{t h r 1}$, where $a<0.9$, is introduced in order to derive the floods duration. It can be considered that $Q_{t h r 2}$ represents a discharge corresponding to the warning level, which announces the beginning of a flood. The threshold $Q_{t h r 2}$ is chosen in such a way to obtain distinct floods. That means that two consecutive floods have to be separated by at least three-times the average time to rise and the discharge between two consecutive flood has to drop below the value of the two thirds of the smaller of the two peaks [61, 62].

For a selected flood, the flood duration $D$ (or the Total duration $T_{t}$ ) corresponds to all discharges $Q(t)>Q_{t h r 2}$ (Figure 3). The volume of interest is the integral of the discharges higher than the threshold [16].

The flood volumes over $Q_{t h r 2}$ are then statistically processed in the same way as used for the maximum discharges, resulting the interval of uncertainty for the volumes $V_{P \%}$ denoted by $\left(V_{L}, V_{U}\right)_{P \%}$. That means an infinite number of volumes $V_{P \%}$ corresponds to the probability of exceedance $P \%$. 


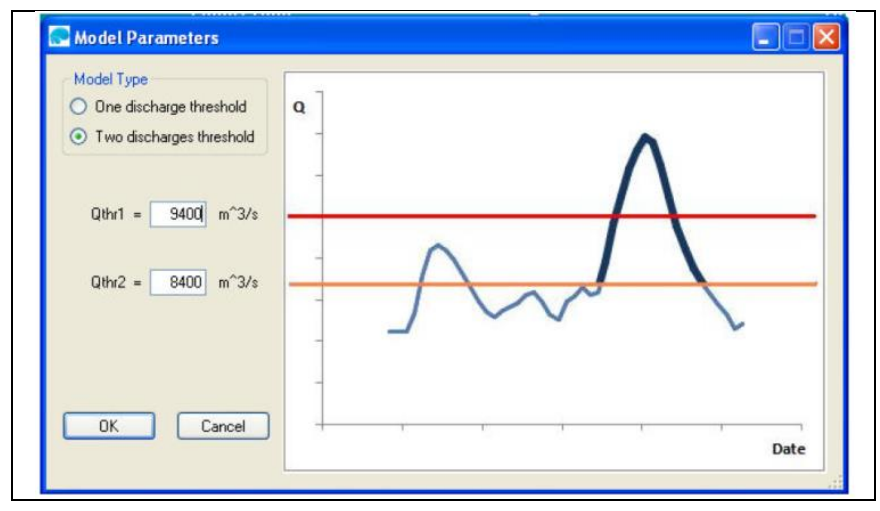

Figure 3. Selection of the floods above the threshold

To conclude, among the statistical distributions only the best ones should be retained, based on statistical tests like chi-square, Kolmogorov or Anderson-Darling. The lower and the upper limits of the selected distributions define the interval of uncertainty. In defining design flood, the upper limit of the maximum discharge and the lower limit of the volume are coupled for each probability of exceedance, and vice versa. The flood characterized by the couple $\left(Q_{P \%}^{\text {upper }} ; V_{P \%}^{\text {lower }}\right)$ will be referred as the Maximum Design Flood (MDF), while the flood defined by the couple $\left(Q_{P \%}^{\text {lower }} ; V_{P \%}^{\text {upper }}\right)$ is called the Maximum Volume Flood (MVF).

These considerations are supported by the bivariate analysis. The cumulative distribution function of maximum discharge and corresponding flood volume represents the simultaneous probability of non-exceedance of two statistical variables:

$$
H\left(Q^{\max }, V\right)_{P \%}=P\left(Q^{\max }<Q_{P \%}^{\max } ; V<V_{P \%}\right),
$$

where $\left(Q^{\max }, V\right)$ is a random vector whose components can be expressed in terms of their marginals:

$$
\begin{gathered}
F\left(Q_{P \%}^{\max }\right)=P\left(Q^{\max }<Q_{P \%}^{\max }\right) \\
F\left(V_{P \%}\right)=P\left(V<V_{P \%}\right),
\end{gathered}
$$

In this case, if $Q^{\max }$ represent maximum registered discharges, $\mathrm{V}$ is the total volume of the flood, adding both volumes above and under the threshold. If $Q_{t h r 2}$ was subtracted from the registered discharges, then $\mathrm{V}$ represents only the volume above the threshold.

As in the case of univariates, in hydrology the probability of exceedance of the same couple of statistical variables (maximum discharge and the corresponding flood volume) is of interest:

$$
\widetilde{H}\left(Q^{\max }, V\right)_{P \%}=P\left(Q^{\max } \geq Q_{P \%}^{\max } ; V \geq V_{P \%}\right),
$$

It can be shown that:

$$
\begin{gathered}
\widetilde{H}\left(Q^{\max }, V\right)_{P \%}=1-P\left(Q^{\max }<Q_{P \%}^{\max }, V<V_{P \%}\right)-P\left(Q^{\max }<Q_{P \%}^{\max }, V \geq\right. \\
\left.V_{P \%}\right)-\quad-\mathrm{P}\left(Q^{\max } \geq Q_{P \%}^{\max }, \quad V<V_{P \%},\right.
\end{gathered}
$$

Thus, $H\left(Q^{\max }, V\right)_{P \%}$ and $\widetilde{H}\left(Q^{\max }, V\right)_{P \%}$ meaning the probability of non-exceedance and the probability of exceedance respectively are not strictly complementary as in the case of univariates.

The design flood, characterized by the probability of exceedance $P \%$ cannot have simultaneously both the maximum discharge $Q_{P \%}^{\max }$ and the volume $V_{P \%}$, which belong to a hydrograph whose probability of exceedance is unknown being defined by the common probability 
of the marginal probabilities of peak and volume [3]. High peak discharge does not necessarily mean high hydrograph volume [63].

That means the point $\left(Q_{P \%}^{\max }, V_{P \%}\right)$ is not situated on the isoline of exceedance probability $\widetilde{H}\left(Q^{\max }, V\right)_{P \%}$, as it can be seen from Figure 4 a.

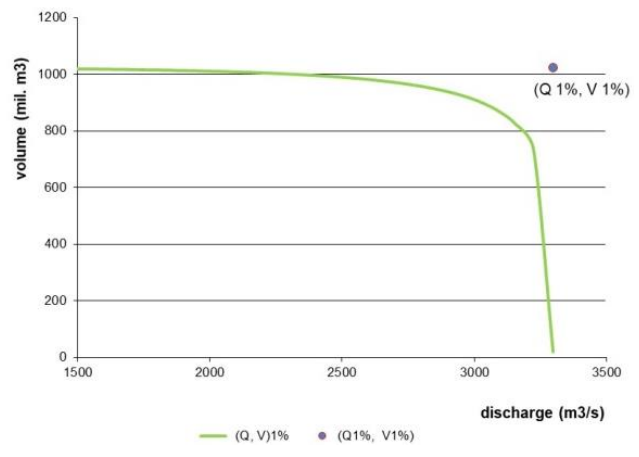

(a)

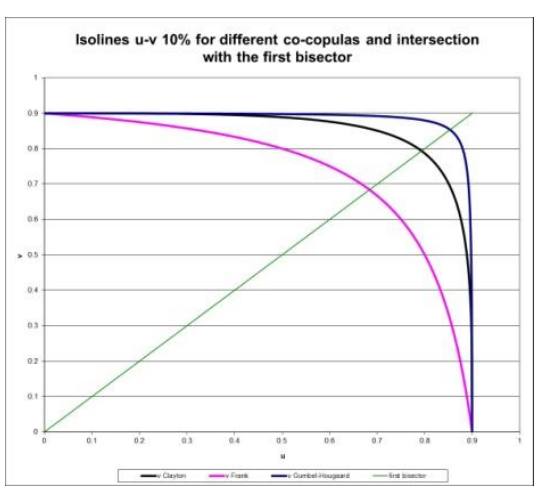

(b)

Figure 4. Bivariate approach: (a) The isoline $\widetilde{H}\left(Q^{\max }, V\right)_{P \%}$ and the point $\left(Q_{P \%}^{\max }, V_{P \%}\right)$ for the probability of exceedance $P \%=1 \%$; (b) Critical point at the intersection of the isolines with the first bisector

An ensemble of couples $\left(Q^{\max }, V\right)_{P \%}$ corresponds to the probability of exceedance $P \%$ of the design flood, each of the two components having a different probability of individual exceedance. Among this ensemble, the most critical combinations correspond to the maximum discharge flood characterized by the pair $\left(Q_{U}^{\max }, V_{L}\right)_{P \%}$, respectively to the maximum volume flood $\left(Q_{L}^{\max }, V_{U}\right)_{P \%}$, where the indexes $U$ and $L$ mean the upper and the lower limit respectively of the interval of uncertainty. This approach is similar to that recommended by Volpi and Fiori [16] in the context of bivariate flood frequency analysis. Another critical couple [16] is the equivalent of the vertex in the plane $(\mathrm{u}, \mathrm{v})$ situated at the intersection of the first bisector with the isoline of exceedance probability (Figure $4 b$ ).

Prohaska and Ilić [22] recommended for flood management issues 4 characteristic points, from which 3 are on the isoline $\widetilde{H}\left(Q^{\max }, V\right)_{P \%}$ corresponding to the probability of exceedance $P \%$, while the $4^{\text {th }}$ is the "maximum possible hydrograph" whose parameters are $\left(Q_{P \%}^{\max }, V_{P \%}\right)$, although the probability of exceedance of this couple is lower than $P \%$.

\subsection{Compactness coefficient and shape of the design flood}

There are the following cases to define the design flood (MDF or MVF):

A. Reproducing the shape of floods that occurred in the past:

A1. A single flood of maximum discharge, respectively another one for the maximum volume characterize the design flood for each probability of exceedance

A2. A family of floods, with different shapes and time to peaks, are defined for each probability of exceedance for MDF, and similarly for MVF.

B. Using a spline function that passes through the points $(0,0),\left(T_{p}, Q_{P \%}^{\max }\right),(D, 0)$ and respecting the compactness coefficient (see Figure 1). 
B1. A single synthetic flood of maximum discharge, respectively another one for the maximum volume for each probability of exceedance.

B2. A family of synthetic floods, with different time to peaks, are defined for each probability of exceedance for MDF, and similarly for MVF.

In the case A1, the shape of the registered floods characterized by the maximum discharge and by the maximum volume is reproduced. In scenario A2, all the floods above the threshold are normalized and then, using a clusterization procedure, they are grouped into classes according to their shape. For instance, the floods can be divided into the following categories: 1 peak, 2 peaks or 3 peaks. The normalised floods with a single peak can be subdivided according to the position of the peak: peak below 0.2 ; peak in the range $(0.1 ; 0.3) ;(0.3 ; 0.4) ;(0.40 ; 0.6)$ or above 0.6 . If necessary, the discretisation can be thinner. For each category or sub-category, the weighted average values of the normalized floods are derived. Instead of a single flood for the maximum discharge flood and the maximum volume flood respectively as in case A1, a family of design floods with different shapes is derived for each probability of exceedance in case A2.

Similar considerations apply to cases B1 and B2, with the difference that spline functions will be used to obtain the shape of synthetic floods.

The normalized floods, which are dimensionless, have the same shape as the original floods and are obtained as follows:

$$
\begin{gathered}
t_{i}=\frac{T_{i}-T_{s}}{T_{t}} \cdot 100 \quad[\%], \\
q_{i}=\frac{Q_{i}-Q_{t h r 2}}{Q_{\max }-Q_{t h r 2}} \cdot 100 \quad[\%],
\end{gathered}
$$

where:

$t_{i}$ - time corresponding to discharge $q_{i}$ value of the dimensionless hydrograph [\%]

$T_{i}$ - time of recording discharge $Q_{i}$ of the registered flood hydrograph [dd/mm/yyyy hh:mm]

$T_{s}$ - time of starting of the registered flood [dd/mm/yyyy hh:mm]

$T_{t}$ - total duration of registered flood [day]

$q_{i}$ - discharge value of the dimensionless hydrograph [\%]

$Q_{i}$ - discharge at the moment $T_{i}$ for the registered hydrograph $[\mathrm{m} 3 / \mathrm{s}]$

$Q_{t h r 2}$ - threshold for separating distinct floods

$Q_{\max }$ - maximum discharge (the peak) of the current flood

The average dimensionless hydrograph of a class is obtained considering the dimensionless hydrographs belonging to the same class. Classes represent groups of dimensionless floods which have a similar shape. Classes clustering can be done manually or automatically. Dimensionless hydrographs within a class are weighted by the following weighting factor:

$$
w_{f}=\frac{Q_{\max (f)}-Q_{t h r 2}}{\sum_{j=1}^{n}\left(Q_{\max (j)}-Q_{t h r 2}\right)},
$$

where:

$w_{f}$ - weighting factor for the dimensionless flood $f[-]$.

$Q_{\max (f)}$ - peak discharge of the dimensionless flood $f\left[\mathrm{~m}^{3} / \mathrm{s}\right]$

$n$ - number of dimensionless floods belonging to the same class [ - ]. 
As an example (Figure 5a), the average dimensionless flood of the Class 2 is the weighted average between dimensionless floods 58 and 67, where the weighting factors are: $w_{58}=0.31$ and $w_{67}=0.69$. The shape of the Class 9 is the weighted average of 8 floods (Figure $5 \mathrm{~b}$ ).

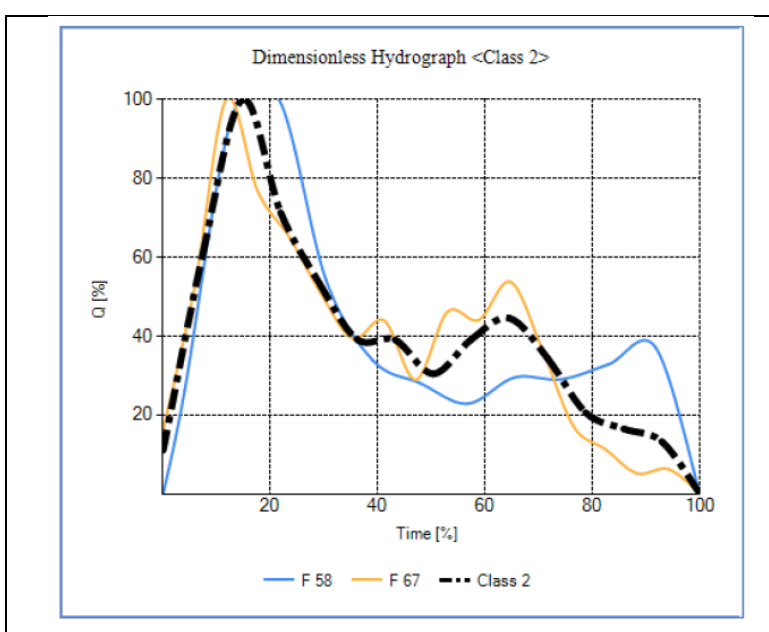

(a)

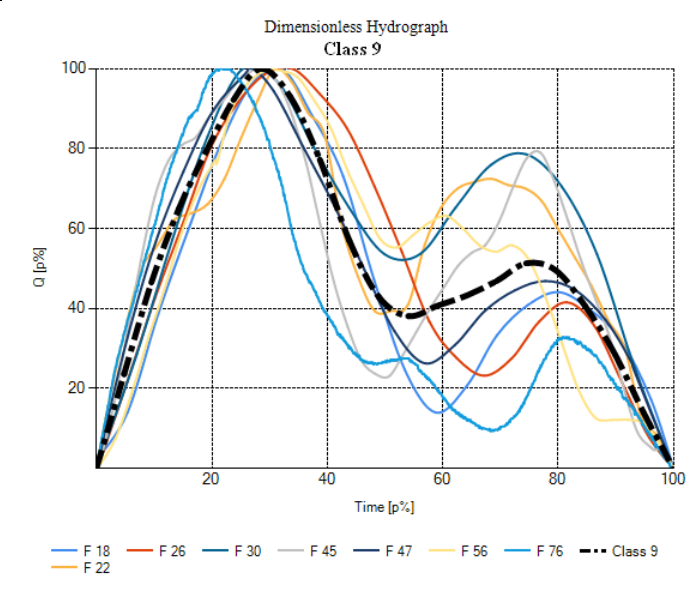

(b)

Figure 5. Examples of average dimensionless floods: (a) Class 2; (b) Class 9

A class can contain one or more floods with similar shape. If a class contains only one flood, it will shape that class.

To obtain the compactness coefficient and the shape of the design flood, proceed as follows:

a) The first $\mathrm{K}$ significant floods are retained in the descending order of the maximum flows. A recommended value is $K \leq 5$. A flood with a particular shape can be excluded, and the next flood will be chosen in descending order of peak flow. In addition, it is advisable to select floods with 2-3 peaks.

b) The selected floods from which the value of the threshold has been deducted are normalized, i.e., they are brought to a percentage scale on both abscissa and ordinate, the value of $100 \%$ corresponding to the flood duration, respectively to the maximum discharge of each flood.

c) The compactness coefficients $\gamma_{k=\overline{1, K}}$ of the dimensionless floods are computed.

The compactness coefficient is obtained as follows for the dimensionless floods:

$$
\gamma=\frac{\sum_{i=2}^{n} \frac{q_{i-1}+q_{i}}{2}\left(t_{i}-t_{i-1}\right)}{q_{\max } \cdot t_{\text {tot }}}=\sum_{i=2}^{n} \frac{q_{i-1}+q_{i}}{2}\left(t_{i}-t_{i-1}\right)
$$

because $q_{\max }=1$ and $t_{\text {tot }}=1$.

d) The dimensionless time to peak $t_{p, k=\overline{1, K}}$ of the normalized floods is also determined.

e) Maximum discharge flood. In the case A1 the shape of the maximum discharge flood will be similar to the shape of the first ranked of the registered flood in descending order of the maximum discharges. The compactness coefficient of this flood is denoted by $\gamma_{1}^{d}$, while the dimensionless time to peak is denoted by $\left(t_{p}\right)_{1}^{d}$. The current time value is $\left(t_{i}\right)_{1}^{d}$ and the corresponding discharge is $\left(q_{i}\right)_{1}^{d}$. The letter $d$ from the exponent has no meaning of power, but of index, and represents discharge. In the case A2, the normalized floods are grouped into classes according to their shape, and then an average dimensionless flood is derived for each 
class. The compactness coefficient will be kept at the value $\gamma_{1}^{d}$, while the time to peak will be different for each class. Similar considerations can be made for the cases B1 and B2: the compactness coefficient is kept at the value $\gamma_{1}^{d}$ in all cases, while the shape of the synthetic floods is given by analytical relations.

f) Maximum volume flood. In the case A1, all the $K$ dimensionless floods are taken into account, and the maximum value of the compactness coefficient is chosen:

$$
\gamma_{j \leq K}^{v}=\max _{k}\left\{\gamma_{k=\overline{1, K}}\right\}
$$

The index $j$ for which $\gamma_{j}^{v}$ is maximum designates the sequence number of the flood in the descending ordered of the maximum discharges. The letter $v$ from the exponent has no meaning of power but of index to indicate volume. The dimensionless time to peak of the maximum volume

flood is denoted by $\left(t_{p}\right)_{j}^{v}$. The current time value is $\left(t_{i}\right)_{j}^{v}$ and the corresponding discharge is $\left(q_{i}\right)_{j}^{v}$. In Scenario A1, the shape of the maximum volume flood will be similar to the shape corresponding to the $j^{\text {th }}$ ranked of the registered flood in descending order of the maximum discharges.

In the case A2, the compactness coefficient of the normalized floods will be kept at the value $\gamma_{j}^{v}$, while the time to peak will be different for each class.

Similar considerations can be made for the cases B1 and B2: the compactness coefficient is kept at the value $\gamma_{j}^{v}$ in all cases, while the shape of the synthetic floods is given by analytical relations.

\subsection{Duration of the synthetic flood}

The flood volume $V$ above the threshold, without any reference to the probability of exceedance $P \%$, is:

$$
V=\gamma\left(Q^{\max }-Q_{t h r 2}\right) D
$$

where :

$$
\begin{aligned}
& V \text { is the flood volume above threshold } Q_{t h r 2} ; \\
& \gamma \text { - the compactness coefficient of the flood; } \\
& Q^{\max } \text { - maximum discharge of the flood, } \\
& Q_{t h r 2} \text { - the threshold; } \\
& D \quad \text { - duration of the synthetic flood. }
\end{aligned}
$$

It was admitted that the compactness coefficient $\gamma_{1}^{d}$ of all maximum discharge floods is the same regardless of the probability of exceedance of the flood. Similarly, $\gamma_{k}^{v}$ is the compactness coefficient of all synthetic floods of maximum volume regardless of the probability of exceedance of the flood.

The duration $D_{P \%}$ of the synthetic flood for the probability of exceedance $P \%$ is calculated with the relation:

$$
D_{P \%}=\frac{V_{P \%}}{\gamma\left(Q_{P \%}^{\max }-Q_{t h r 2}\right)},
$$

where :

$V$ is the flood volume above threshold $Q_{t h r 2}$; 


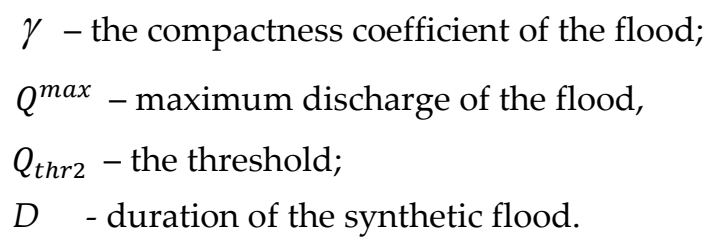

It was admitted that the compactness coefficient $\gamma_{1}^{d}$ of all maximum discharge floods is the same regardless of the probability of exceedance of the flood. Similarly, $\gamma_{k}^{v}$ is the compactness coefficient of all synthetic floods of maximum volume regardless of the probability of exceedance of the flood.

The duration $D_{P \%}$ of the synthetic flood for the probability of exceedance $P \%$ is calculated with the relation:

$$
D_{P \%}=\frac{V_{P \%}}{\gamma\left(Q_{P \%}^{\max }-Q_{t h r 2}\right)},
$$

where the parameters $\gamma, Q_{P \%}^{\max }, V_{P \%}$ are replaced by $\gamma_{1}^{d},\left(Q_{U}^{\max }\right)_{P \%},\left(V_{L}\right)_{P \%}$ for the maximum discharge flood and by $\gamma_{j}^{v},\left(Q_{L}^{\max }\right)_{P \%},\left(V_{U}\right)_{P \%}$ for the maximum volume flood respectively.

The synthetic flood duration $D_{P \%}$ has a variable size, depending on the probability of exceedance $P \%$. For the same probability of exceedance, the duration $D_{P \%}$ is shorter for the maximum discharge flood compared to the maximum volume flood.

\subsection{Time to peak of the design flood}

In the cases A1 and B1 (a single flood for MDF and another one for MVF), the time to peak for the design flood is:

$$
\left(T_{p}\right)_{P \%}=t_{p} \cdot D_{P \%}
$$

where $t_{p}$ is replaced by $\left(t_{p}\right)_{1}^{d}$ for the maximum discharge flood and by $\left(t_{p}\right)_{j}^{v}$ for the maximum volume flood. The computed value for $\left(T_{p}\right)_{P \%}$ corresponds to maximum discharge flood or to maximum volume flood respectively.

In the cases A2 and B2 (a family of design floods) the time to peak of the normalized floods in each class is computed with a similar relation, $D_{P \%}$ being the same no matter the class.

\subsection{Construction of synthetic flood waves}

As previously mentioned, a synthetic flood is a discharge hydrograph defined by the following elements: peak discharge, flood volume, duration and shape.

The statistical processing of the annual maximum discharges is undertaken by EasyFit commercial software, while the other steps in defining the design floods are made using different in-house software IHS.

The algorithm for the construction of synthetic floods is the following:

1) Identify the period with available data for analysis.

2) Select the following data:

a) the maximum annual discharges;

b) the time series of discharges exceeding a certain threshold. The threshold $Q_{t h r}$ is chosen in principle so that the number of floods is equal to the number of years. Otherwise, the 
relationships presented in paragraph 2.2 shall be taken into account in determining the annual probabilities of exceedance.

3) Choose the threshold $Q_{t h r 2}$ and determine the floods' volume above it.

4) Test the independence, homogeneity and stationarity of the obtained series.

5) Generate and process the statistical distributions of the maximum annual discharges and establish the confidence interval or the uncertainty interval, depending how many distributions are considered:

a) if a single statistical distribution is used, in order to take into account the uncertainty the interval corresponding to a chosen confidence level (95\% or less) is calculated.

b) if several statistical distributions are used to extrapolate the empirical distribution, the inadequate distributions are eliminated using statistical tests. The upper and lower envelope of the discharges calculated with the retained distributions represent the uncertainty interval of discharges.

6) Process the floods volume above the threshold $Q_{t h r 2}$ in the same way as the maximum annual discharges, resulting in the uncertainty interval of the flood volumes.

7) Determine the compactness coefficient of the floods above the threshold distinctly for the maximum discharge floods and for the maximum volume floods respectively:

a) the first $\mathrm{K}$ floods ( $\mathrm{K}<5$ usually) are selected in descending order of the maximum discharge;

b) the selected floods (discharges above the threshold $Q_{t h r 2}$ ) are normalized;

c) the compactness coefficient $\gamma_{k}$ for each flood $k=\overline{1, K}$ is determined;

8) Normalize the selected floods (discharges above the threshold $Q_{t h r 2}$ ).

9) Establish the shape of the synthetic flood

a) In the case A1 for the maximum discharge flood, the shape of the flood ranked first following the descending order of the maximum discharges is selected. The compactness coefficient of this flood is $\gamma_{1}^{d}$, while the dimensionless time to peak is $\left(t_{p}\right)_{1}^{d}$. For the maximum volume flood, the flood shape corresponding to the maximum value of the compactness coefficient $\gamma_{j}^{v}$ is chosen. The dimensionless time to peak of the maximum volume flood is denoted by $\left(t_{p}\right)_{j}^{v}$ and is different for MDF and MVF.

b) In the case A2, the normalized floods are grouped into classes according to their shape (see Figure 5) and then an average dimensionless flood is derived for each class (Figure 6). The compactness coefficient will be kept as in Scenario A1 for MDF and MVF respectively, but the time to peak is different for each class.

c) Similar considerations are made for the cases B1 and B2.

10) Calculate the flood duration $D_{P \%}^{M D F}$ for the pairs $\left(Q_{U}^{\max }, V_{L}\right)_{P \%}$ that characterize the maximum discharge flood and the duration $D_{P \%}^{M V F}$ for the pairs $\left(Q_{L}^{\max }, V_{U}\right)_{P \%}$ that characterize the maximum volume flood respectively, corresponding to each probability of exceedance $\mathrm{P} \%$. The flood duration is expressed in days, making the necessary transformations. 


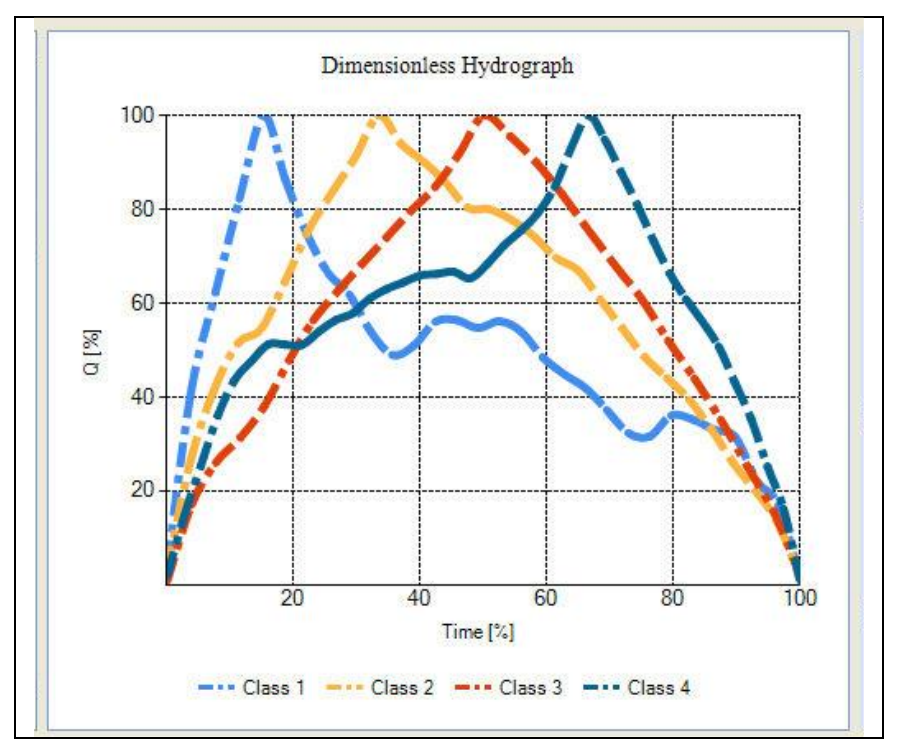

Fig. 6 Average dimensionless floods for different classes

11) Multiply the ordinates of the maximum discharge flood and maximum volume flood respectively with the maximum discharge (from which the threshold $Q_{t h r}$ was substracted) corresponding to the probability of exceedance $\mathrm{P} \%$, and add to the ordinates thus obtained the threshold value $Q_{t h r 2}$. The timing in days on the abscissa is obtained by multiplying the adimensional time with the flood duration. Thus for the maximum discharge flood one obtains:

$$
\begin{aligned}
\left(Q_{i}^{M D F}\right)_{P \%}= & \left(q_{i}\right)_{1}^{d} \cdot\left(\left(Q_{U}^{\max }\right)_{P \%}-Q_{t h r 2}\right)+Q_{t h r 2} \\
& \left(T_{i}^{M D F}\right)_{P \%}=\left(t_{i}\right)_{1}^{d} \cdot D_{P \%}^{M D F},
\end{aligned}
$$

For the maximum volume flood the coordinates of the synthetic flood are:

$$
\begin{aligned}
\left(Q_{i}^{M V F}\right)_{P \%}= & \left(q_{i}\right)_{j}^{v} \cdot\left(\left(Q_{L}^{\max }\right)_{P \%}-Q_{t h r 2}\right)+Q_{t h r 2}, \\
& \left(T_{i}^{M V F}\right)_{P \%}=\left(t_{i}\right)_{j}^{v} \cdot D_{P \%}^{M V F},
\end{aligned}
$$

The notations keep their original meaning. The indexes MDF and MVF refer to maximum discharge flood and maximum volume flood.

The time to peak $\left(T_{p}^{M D F}\right)_{P \%}$ for MDF and $\left(T_{p}^{M V F}\right)_{P \%}$ for MVF respectively are implicitly obtained with the above relations. In the case A1 there is only one design flood for the MDF and another one for MVF respectively, but with different compactness coefficients and times to peak. They reproduce the shape of significant floods which occurred in the past. In the case A2 a family of design floods for MDF and MVF respectively, which reproduce shapes of registered floods in the past, is obtained. The design floods in each category or sub-category for maximum discharge flood are characterized by the same parameters: $Q_{P \%}^{\max }, D_{P \%}, \gamma$, but the shape and the peak time are different. The same rule applies to the maximum volume flood, but $Q_{P \%}^{\max }$ and $D_{P \%}$ are different from the similar parameters of the maximum discharge flood.

In cases B1 and B2, the synthetic flood is characterized by the same parameters, $\left(Q_{U}^{\max }, T_{p}^{M D F}, D^{M D F}, V_{L}\right)_{P \%}$ and $\left(Q_{L}^{\max }, T_{p}^{M V F}, D^{M V F}, V_{U}\right)_{P \%}$ respectively, but the shape is mathematically derived. A spline function unites the points $\left(0, Q_{t h r 2}\right) ;\left(T_{p}^{M D F}, Q_{U}^{\max }\right)$ and $\left(D^{M D F}, Q_{t h r 2}\right)$ for the MDF and $\left(0, Q_{t h r 2}\right),\left(T_{p}^{M V F}, Q_{L}^{\max }\right) ;\left(D^{M V F}, Q_{t h r 2}\right)$ for the MVF by keeping the corresponding flood volume. In the case $\mathrm{B} 1$, the time to peak $T_{p}$ as well as the flood duration $D$ 
have a different value for MDF and MVF. In the case B2 the time to peak $T_{p}$ is different for each class of floods, being at the same time different for MDF and MVF.

\section{Case studies}

In the following, 2 case studies will be presented. They were initiated in international cooperation, but were developed after the projects' finalization. The first case study was analysed in the frame of Danube Floodrisk project (DANUBE FLOODRISK - PA 05 (danube-region.eu) [64] SEE (South East Europe) transnational and interregional programme, while the second case study was undertaken to support the Joint Operational Programme Romania-Ukraine-Republic of Moldova EastAvert project [65]. In both cases, the data for the Romanian territory were provided by the National Institute of Hydrology and Water Management, Bucharest, Romania.

The Danube River and its tributaries are the object of numerous initiatives for cooperation, like International Commission for the Protection of the Danube River (ICPDR) created in 1998 to promote policy agreements and the setting of joint priorities and strategies for improving the state of the Danube and its tributaries, or the EU Strategy for the Danube Region (EUSDR) endorsed in 2011 by the European Council.

An important scientific research work [51] was completed in 2019 by scientists from eleven countries of the Danube River Basin. The work was performed and carried out with the involvement of the National Committees of IHP UNESCO of the Regional cooperation of the countries in the Danube River Basin under the coordination of the Institute of Hydrology of the Slovak Academy of Sciences.

\subsection{Case study no. 1}

The complete time series of maximum daily discharges registered at Turnu Măgurele on Danube River from 1931 till 2008 was available for the statistical analysis (Figure 7).

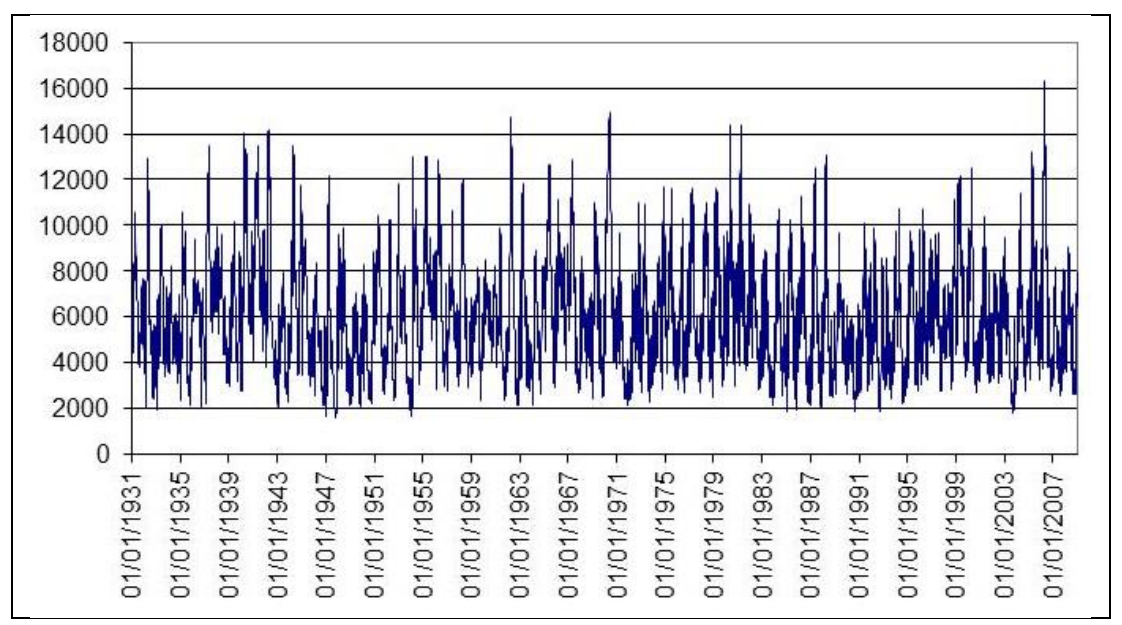

Figure 7. Complete time series of discharges registered at Turnu-Măgurele (source: National Institute of Hydrology and Water Management, Romania)

The time series were checked for potential trend, finding that the hypothesis of stationarity is justifiable. A future direction of research is to consider the time dependency of the distribution parameters [42] in order to derive the worst possible flood for a given probability of exceedance. However, the interval of uncertainty, as it is defined, is able to include a possible non-stationarity of 
the hydrological data. The results of the statistical tests concerning the mutual independence and identical distribution, the homogeneity and the lack of trend of the annual maximum discharges are presented in Table 1.

Table 1. Results of the statistical tests

\begin{tabular}{|c|c|c|c|c|c|}
\hline Statistical Test & Statistics & $\begin{array}{c}|Z| \\
\text { statistics }\end{array}$ & $\mathbf{Z}$ quantile & $\begin{array}{c}\text { First } \\
\text { degree } \\
\text { error }\end{array}$ & Conclusions \\
\hline Wald-Wolfowitz & $\mathrm{R}=31$ & 1.74264 & $\begin{array}{c}Z_{0.05}=1.65 \\
Z_{0.025}=1.96\end{array}$ & 0.0814 & $\begin{array}{c}\text { Mutual } \\
\text { independence } \\
5 \% \text { threshold }\end{array}$ \\
\hline Turning point & $\mathrm{T}=50$ & 0.18115 & $Z_{0.05}=1.65$ & 0.85626 & $\begin{array}{c}\text { i.i.d } \\
10 \% \text { threshold }\end{array}$ \\
\hline Mann-Whitney-Wilcoxon & $\mathrm{W}=700$ & 0.03179 & $Z_{0.05}=1.65$ & 0.97464 & $\begin{array}{c}\text { Mutual } \\
\text { Homogeneity } \\
10 \% \text { threshold }\end{array}$ \\
\hline Mann-Kendall & $\mathrm{T}=-115$ & 0.49192 & $Z_{0.05}=1.65$ & 0.62278 & $\begin{array}{c}\text { No trend } 10 \% \\
\text { threshold }\end{array}$ \\
\hline
\end{tabular}

According to the statistical tests, in all cases the null hypothesis (mutual independence, mutual homogeneity and lack of trend) is accepted with threshold $10 \%$. The only exception is the Wald-Wolfowitz test, where the null hypothesis is accepted for $5 \%$ threshold, but it is rejected for $10 \%$ threshold.

The explanation for the lack of trend of the annual maximum discharges is the large size of the Danube river basin, which is able to compensate at least in the lower Danube reaches the local effects of the climate changes. Thus, one can suppose that for the lower Danube the variation of the discharges $Q_{P \%}$ is due mainly to natural variability.

The aleatory uncertainty for a LP3 distribution was put into evidence by analysing different lengths of registered or generated data at Turnu Măgurele on Danube River, while the epistemic uncertainty analysis was based on the selection of a number of statistical distributions which fit relatively well the selected discharges from 1931 till 2008 at the same gauge station.

\subsubsection{Aleatory uncertainty}

For the beginning, the initial selection of the 78 values of the maximum annual discharges was split into two series: the first 30 values were statistically processed considering log Pearson 3 distribution, and then new values were added followed by new statistical processing. The maximum discharges corresponding to $0.1 \%$ probability of exceedance are in the range $(18800,20050) \mathrm{m}^{3} / \mathrm{s}$ (Figure 8a).

In the following, based on the sample data of maximum annual discharges, a set of 1000 values following the log Pearson 3 distribution and keeping the same statistical parameters were randomly generated. The discharges corresponding to different probabilities of exceedance were computed for the generated values, by increasing step by step the number of processed discharges from 80 to 500 .

The evolution of the maximum discharge values corresponding to $0.1 \%$ probability of exceedance versus the increase of the sample volume of generated values is presented in Figure 8b. 
For generated values, the maximum discharges corresponding to $0.1 \%$ probability of exceedance are in the range $(18600,20550) \mathrm{m}^{3} / \mathrm{s}$. One can notice the strong variability of the maximum discharges corresponding to the first 200 registered plus generated values, and the relative stabilization of the discharges for larger sample volumes. After stabilization, the maximum discharges corresponding to $0.1 \%$ probability of exceedance are in the range $(18600,19620) \mathrm{m}^{3} / \mathrm{s}$. This result is a consequence of the law of large numbers, according to which the average of the results obtained from a large number of trials is close to the expected value of the statistics.

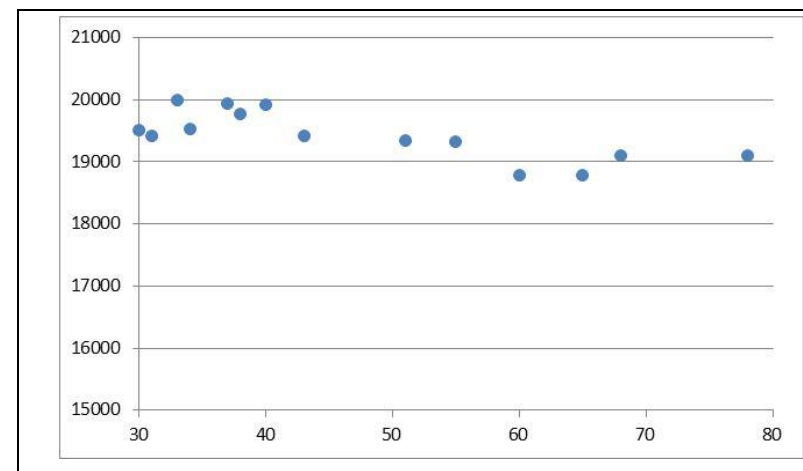

(a)

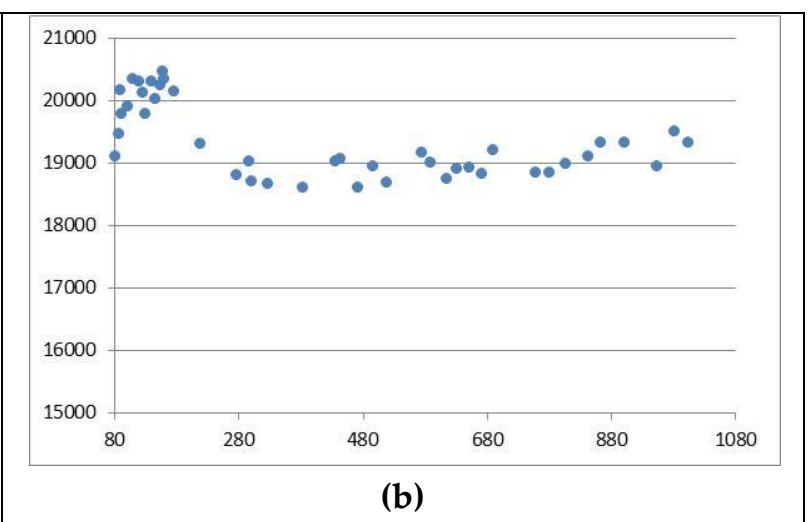

(b)

Figure 8. Discharges $Q_{0.1 \%}$ versus volume of the sample: (a) registered discharges; (b) registered discharges plus generated values.

The graphical representations of the cumulative distribution function were plotted on the probability format, allowing the visualization of the cumulative curve. The dark solid line in Fig. 9 represents the curve of the probabilities of exceedance for the initial set of 78 annual maximum discharges, while the grey solid lines correspond to different volumes of the sample.

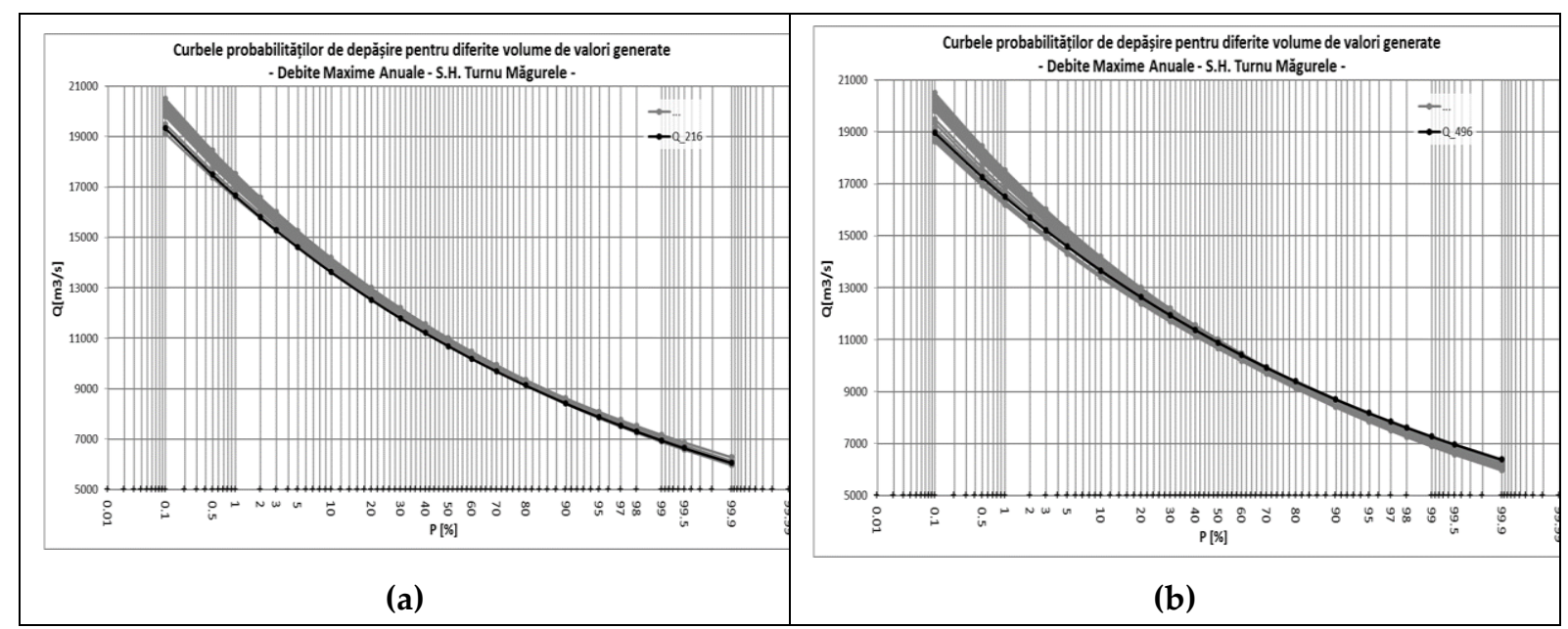

Figure 9. Cumulative distribution curves for different samples volumes: (a) 216 values; (b) 496 values

The cumulative curves cover a quite large range of values for medium and rare probabilities of exceedance. Figure 9 can be considered an illustration of the aleatory uncertainty. Thus, for the probability of exceedance $0.1 \%$, the maximum discharge is in the range $(18611,20483) \mathrm{m}^{3} / \mathrm{s}$, which means a difference of $1872 \mathrm{~m}^{3} / \mathrm{s}$, or a percentage of $10 \%$. The percentage is $8 \%$ for the probability of 
exceedance $1 \%$ and decreases with the increase of the probability of exceedance, being minimum in the central part of the distribution.

\subsubsection{Epistemic uncertainty}

Another statistical processing, aiming to put into evidence the epistemic uncertainty, was made for the same data in the frame of Danube Floodrisk project [64]. Using EasyFit software, a large number of statistical distributions were analysed. All these models are fitted to data and compared using conventional goodness-of fit tests. However, all tests of the statistical model adequacy are based on the central range of the sample, while the adequacy should be mainly tested for the extreme range of observations in order to estimate high events corresponding to low probabilities of exceedance [48]. But extreme values are rarely available and raise problems related to their empirical probability of exceedance. A quite recent approach in Romania [66], but not yet in the current practice, is to use a large number of theoretical distributions and to order them according to their adequacy based on statistical tests. For each probability of exceedance, a histogram showing the distribution of the computed values is obtained. In Figure 10 the empirical distribution, the lower and the upper limits of the maximum uncertainty interval are represented. At the same time, for the probability of exceedance $0.1 \%$ and $1 \%$ histograms of the computed discharges are derived. If necessary, a statistical characterization of the theoretical discharges can be derived.

However, some statistical distributions lead to a very wide spread of discharges especially for low probabilities of exceedance. For this reason, the distributions were ordered according to their adequacy based on statistical tests (Kolmogorov-Smirnov, Anderson-Darling or Chi-Squared test).

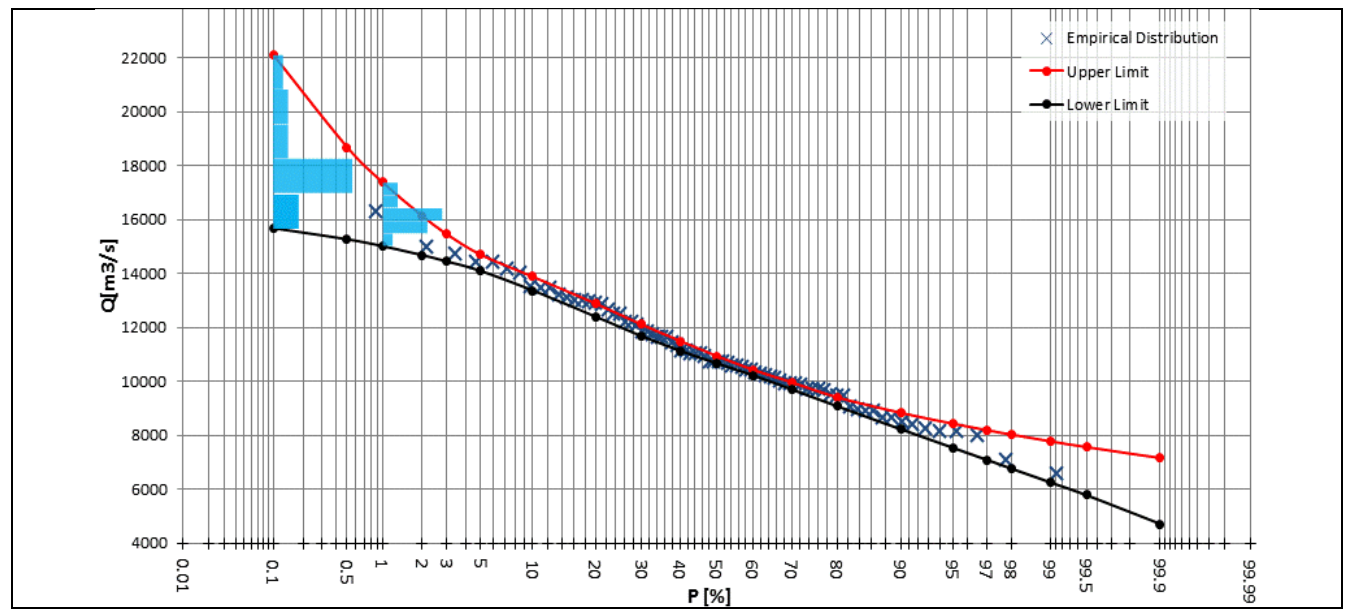

Figure 10. Uncertainty interval of the maximum discharges at Turnu Măgurele gauge station considering 30 distributions (IUGG, 2016)

The results obtained using the first 9 ranked distributions according to Kolmogorov-Smirnov test are presented in Table 2 and Figures 11 and 12. The retained uncertainty interval is included in the maximum uncertainty interval from Figure 10. For example, for $0.1 \%$ AEP the maximum uncertainty limits are $(15700-22100)$, while the retained interval based on the first 9 ranked distributions is $(16221$ - 19646) for POT and $(17317$ - 19884) for BM approach. 


\begin{tabular}{|c|c|c|c|c|c|c|}
\hline \multirow{2}{*}{$\mathbf{P \%}$} & \multicolumn{2}{|c|}{$\begin{array}{c}\text { POT } \\
\left(\mathbf{m}^{3} / \mathbf{s}\right)\end{array}$} & \multicolumn{2}{c|}{$\begin{array}{c}\text { POT* } \\
\left(\mathbf{m}^{3} / \mathbf{s}\right)\end{array}$} & \multicolumn{2}{c|}{$\begin{array}{c}\text { BM } \\
\left(\mathbf{m}^{3} / \mathbf{s}\right)\end{array}$} \\
\hline 0.1 & 8321 & 11346 & 16621 & 19646 & 17317 & 19884 \\
\hline 1 & 7453 & 8238 & 15753 & 16538 & 15825 & 16888 \\
\hline 10 & 5133 & 5450 & 13433 & 13750 & 13541 & 13679 \\
\hline
\end{tabular}

* Values from statistical processing to which the threshold value was added

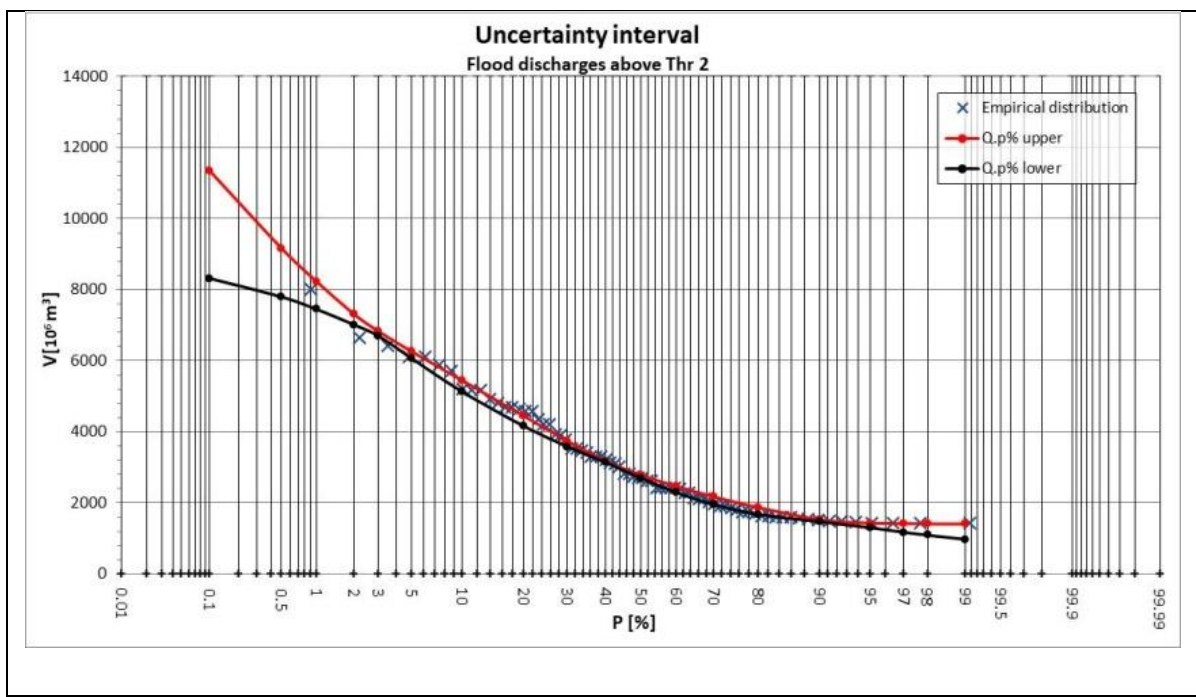

Figure 11. Uncertainty interval of the maximum discharges POT at Turnu Măgurele gauge station

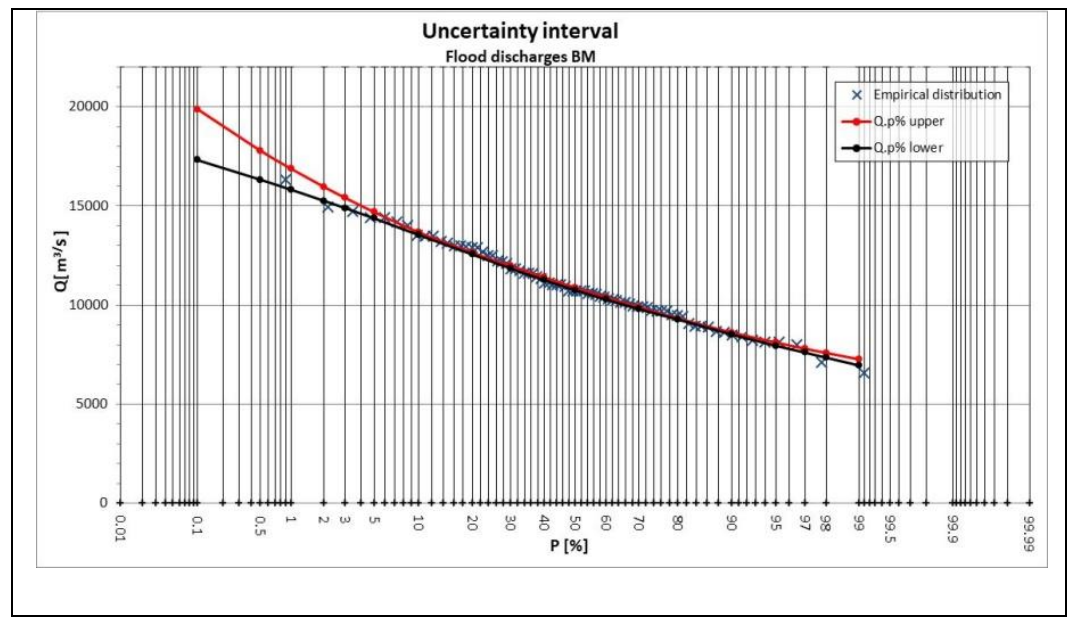

Figure 12. Uncertainty interval of the annual maximum discharges at Turnu Măgurele gauge station

According to Table 2, the uncertainty interval for $1 \%$ annual probability of exceedance is in the range (15825 -16888) m³/s. The maximum discharge registered at Turnu Măgurele during the 2006 flood on 23-24 of April was $16300 \mathrm{~m}^{3} / \mathrm{s}$ and according to INHGA corresponds to $1 \%$ probability of exceedance. This discharge fits perfectly between the limits of the uncertainty interval. At the same time, the interval of aleatory uncertainty for $1 \%$ annual probability of exceedance (Figure 8 ) is in the range (16000-17800) m³/s. The maximum discharge registered at Turnu Măgurele during the 2006 flood is again within these limits. 


\subsubsection{Flood volumes}

The HIS software was used for the separation of the significant floods, using all daily data for the discharges between 1931-2008. The threshold for floods selection is $Q_{t h r 1}=9700 \mathrm{~m}^{3} / \mathrm{s}$, while $Q_{t h r 2}=8300 \mathrm{~m}^{3} / \mathrm{s}$. All discharges greater than $8300 \mathrm{~m}^{3} / \mathrm{s}$ were taken into consideration for computing the flood volume, followed by statistical processing of the volumes undertaken with EasyFit software. The obtained results are presented in Figure 13 and Table 3.

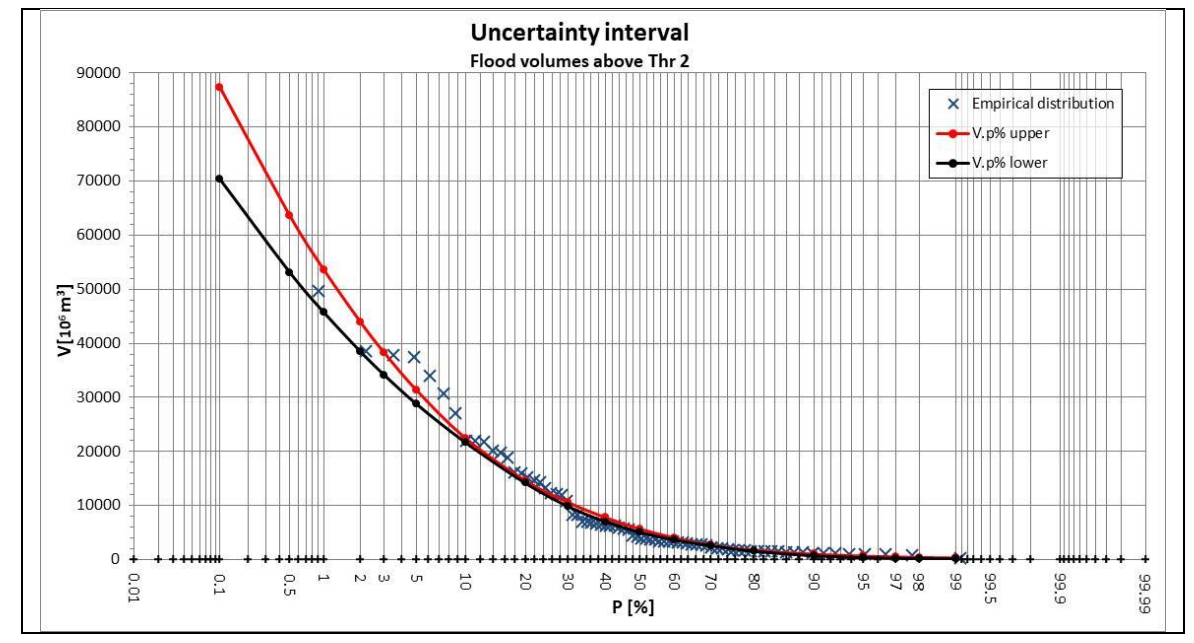

Figure 13. Uncertainty interval of the flood volumes above $Q_{t h r 2}$ at Turnu Măgurele gauge station

Table 3. Flood volumes above $Q_{t h r 2}$ at Turnu-Măgurele gauge station

\begin{tabular}{|c|c|c|}
\hline $\mathbf{P \%}$ & $\begin{array}{c}\text { V lower } \\
\left(\mathbf{1 0}^{\mathbf{6}} \mathbf{m}^{3}\right)\end{array}$ & $\begin{array}{c}\text { V upper } \\
\mathbf{( 1 0}^{\mathbf{6}} \mathbf{m}^{\mathbf{3}}\end{array}$ \\
\hline 0.1 & 70384 & 87390 \\
\hline 1 & 45768 & 53677 \\
\hline 10 & 21633 & 22428 \\
\hline
\end{tabular}

\subsubsection{Flood shape}

The HIS software separates the floods according to the threshold values $\left(Q_{t h r 1}=9700\right.$ and $\left.Q_{t h r 2}=8300 \mathrm{~m} 3 / \mathrm{s}\right)$. In the following table the first 5 floods in decreasing order of the maximum discharge, as well as their main characteristics (starting date, maximum discharge, total volume, volume above the threshold $Q_{t h r 2}$, compactness (shape) coefficient, time to peak and total duration above $Q_{t h r 2}$ ) are presented.

Table 4. Floods at Turnu-Măgurele gauge station and their parameters

\begin{tabular}{|c|c|c|c|c|c|c|c|c|}
\hline \multicolumn{9}{|c|}{ Floods Data } \\
\hline $\mathrm{N}$ & Date & QMax [... & Vol [... & VolSu... & Shape ... & Tp [day] & Tt [day] & $\wedge$ \\
\hline 80 & $07 / 03 / 2006$ & 16300 & 94198 & 31880 & 0.53 & 45.9 & 86.9 & \\
\hline 38 & $14 / 02 / 1970$ & 14940 & 161521 & 49641 & 0.55 & 106.3 & 156.0 & \\
\hline 31 & $13 / 03 / 1962$ & 14700 & 78827 & 21642 & 0.49 & 40.7 & 79.7 & \\
\hline 55 & $12 / 03 / 1981$ & 14400 & 45298 & 14292 & 0.63 & 17.2 & 43.2 & \\
\hline 54 & $30 / 04 / 1980$ & 14400 & 47509 & 12370 & 0.48 & 26.0 & 49.0 & \\
\hline
\end{tabular}


Taking into consideration the compactness coefficient, the floods that occurred in 2006 and 1981 (Figure 14) were considered for the next steps, by skipping the flood clusterization. Based on the dimensionless floods (Figure 15), synthetic floods were obtained both for maximum discharge flood and for maximum volume flood. In the following only the synthetic floods for Qupper_Vlower (Class1) and Qlower_Vupper (Class 2) are presented (Figures 16 and 17; Tables 5 and 6).

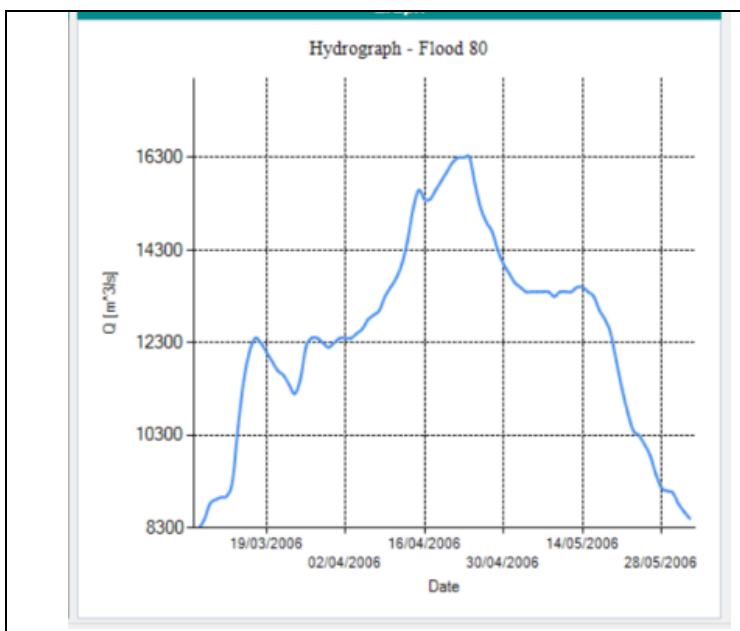

(a)

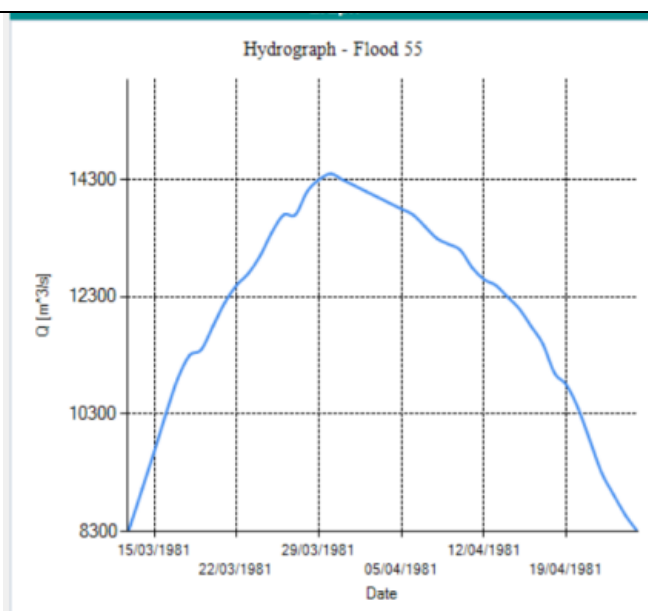

(b)

Figure 14 Significant floods at Turnu Măgurele gauge station: (a) 2006 flood; (b) 1981 flood

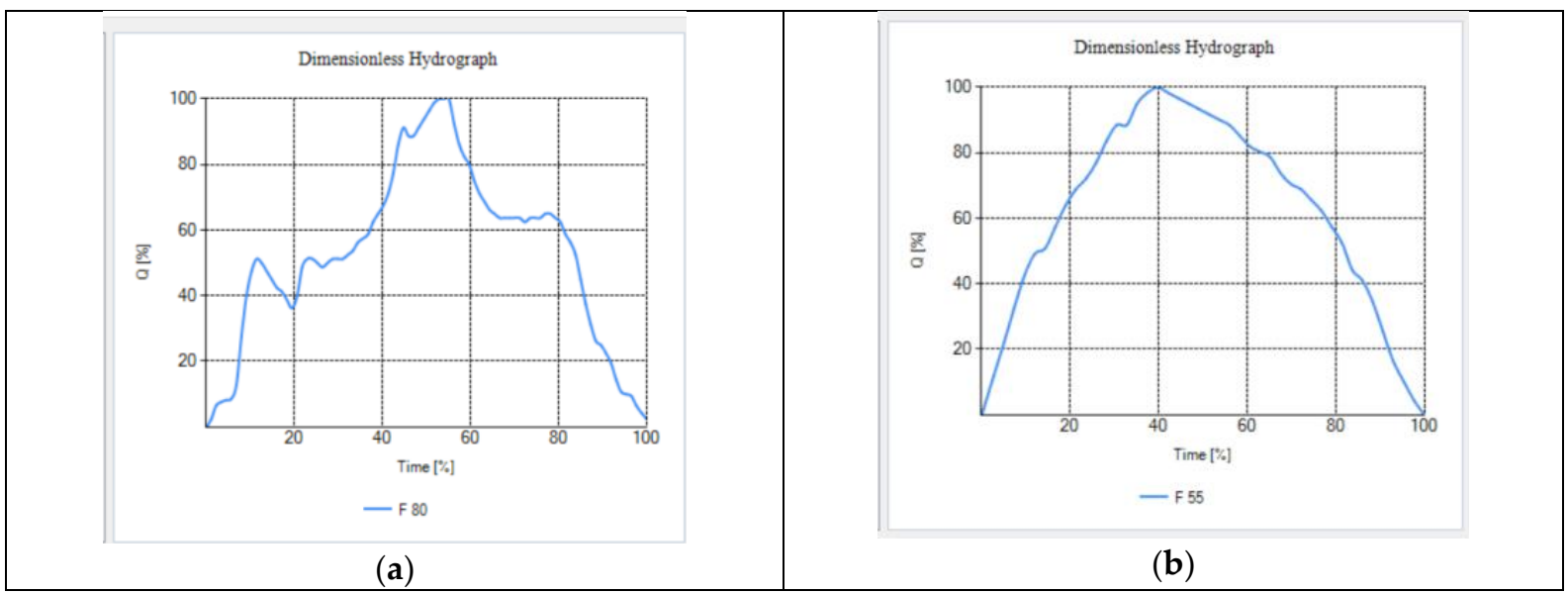

Figure 15. Dimensionless floods: (a) Class 1; (b) Class 2

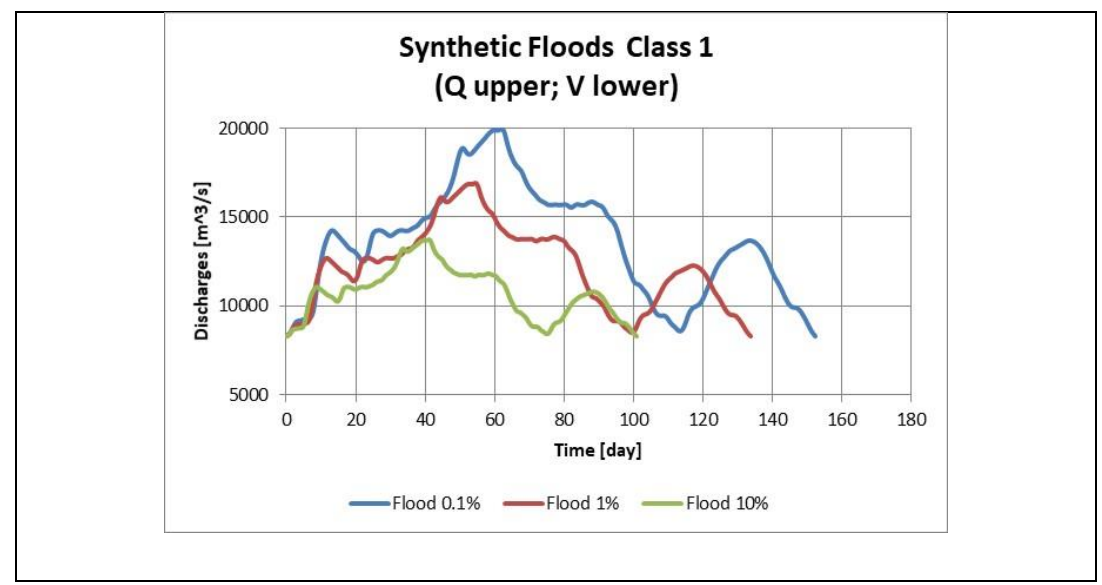

Figure 16. Design Floods (Q upper; V lower) from Class 1 
Table 5. Main parameters of synthetic floods from Class 1 at Turnu-Măgurele

\begin{tabular}{|c|c|c|c|c|}
\hline $\mathbf{P \%}$ & $\begin{array}{c}\text { Q upper } \\
\mathbf{( m 3 / s )}\end{array}$ & $\begin{array}{c}\text { V lower above } \\
\text { threshold } \\
\mathbf{( 1 0 ^ { 6 }} \mathbf{~ m}^{\mathbf{3}}\end{array}$ & $\begin{array}{c}\text { Total V lower } \\
\left.\mathbf{( 1 0}^{\mathbf{6}} \mathbf{m}^{3}\right)\end{array}$ & $\begin{array}{c}\text { Flood duration } \\
\text { above threshold } \\
\text { (days) }\end{array}$ \\
\hline 0.1 & 19884 & 70384 & 179720 & 152 \\
\hline 1 & 16888 & 45768 & 141656 & $134^{*}$ \\
\hline 10 & 13679 & 21633 & 94004 & 101 \\
\hline
\end{tabular}

* In 2006 the maximum discharge was $16300 \mathrm{~m} 3 / \mathrm{s}$, the flood volume above the threshold $\left(8300 \mathrm{~m}^{3} / \mathrm{s}\right)$ was 37301 mil. $\mathrm{m}^{3}$ and the flood duration above the threshold was 117 days.

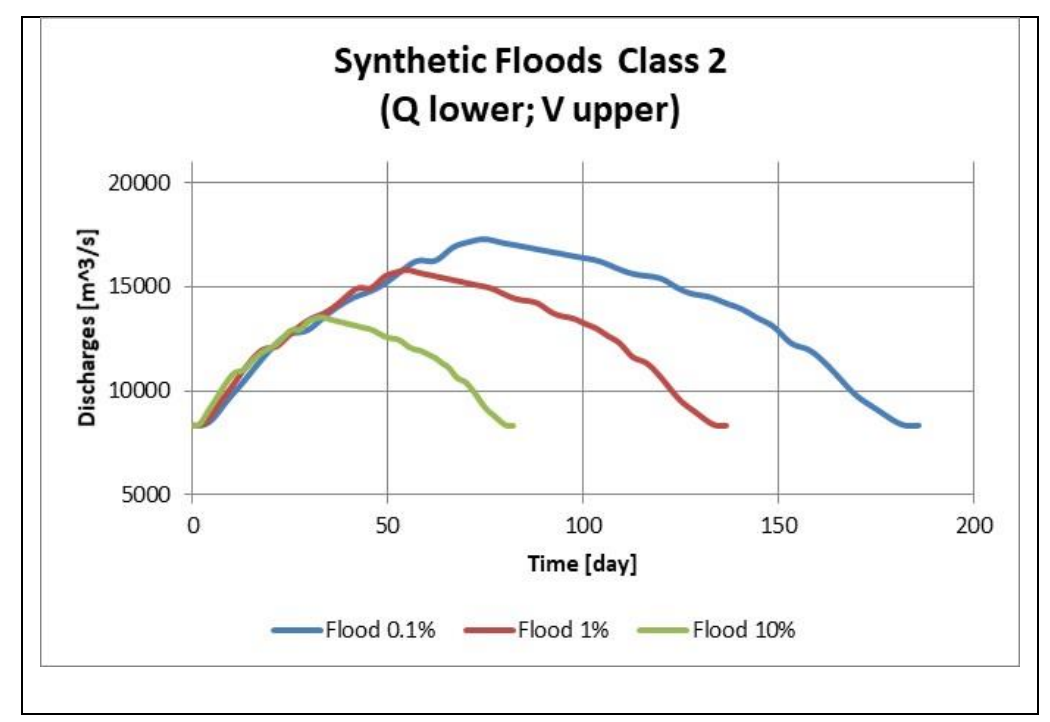

Figure 17. Design Floods (Q lower; V upper) from Class 2

Table 6. Main parameters of synthetic floods Class 2 at Turnu-Măgurele

\begin{tabular}{|c|c|c|c|c|}
\hline $\mathbf{P \%}$ & $\begin{array}{c}\text { Q lower } \\
\mathbf{( m 3 / s )}\end{array}$ & $\begin{array}{c}\text { V upper above } \\
\text { threshold } \\
\left.\mathbf{( 1 0}^{\mathbf{6}} \mathbf{m}^{3}\right)\end{array}$ & $\begin{array}{c}\text { Total V upper } \\
\left.\mathbf{( 1 0}^{\mathbf{6}} \mathbf{m}^{3}\right)\end{array}$ & $\begin{array}{c}\text { Flood duration } \\
\text { above threshold } \\
\text { (days) }\end{array}$ \\
\hline 0.1 & 17317 & 87390 & 220534 & 185 \\
\hline 1 & 15835 & 53677 & 151682 & $137^{*}$ \\
\hline 10 & 13541 & 22428 & 81231 & 82 \\
\hline
\end{tabular}

* In 1970 the maximum discharge was $14940 \mathrm{~m}^{3} / \mathrm{s}$, the flood volume above the threshold $\left(8300 \mathrm{~m}^{3} / \mathrm{s}\right)$ was 49637 mil. $\mathrm{m}^{3}$, and the flood duration above the threshold was 157 days.

\subsection{Case study no. 2}

Rădăuți-Prut gauge station is located on Prut River, about 125 km upstream Stânca-Costești reservoir. It is not influenced by the backwater effect, even at exceptional water levels in the reservoir. The catchment area in the dam section is 12,000 $\mathrm{km}^{2}$. Among the 247 large dams in Romania, Stanca - Costesti dam is ranked as 49 in terms of dam height and is the second, after Iron Gates on Danube in terms of reservoir volume, having a the total capacity 1,285 mil.m $\mathrm{m}^{3}$ The surface area of the reservoir is $77 \mathrm{~km}^{2}$, while its length at the maximum water level during floods is about $120 \mathrm{~km}$. The flood control storage, between the top of the conservation level and the top of the 
surcharge pool (the maximum allowed water level in the reservoir during rare floods corresponding to $0.1 \%$ probability of exceedance of the maximum discharge), is 665 mil.m ${ }^{3}$.

In the first decade of $21^{\text {st }}$ century two major floods occurred: the first, between 25 July - 02 August 2008, which was characterized by a very compact shape and a maximum discharge of 3520 $\mathrm{m} 3 / \mathrm{s}$ and a volume of about $1.16 \times 10^{9} \mathrm{~m}^{3}$ (Figure 18a), while the second one, in 2010 had the maximum discharge of $2040 \mathrm{~m} 3 / \mathrm{s}$, a very large duration (19.06 - 8.08.2010) and an exceptional volume of $2.45^{-1} 10^{9} \mathrm{~m}^{3}$ (Figure $18 \mathrm{~b}$ ).

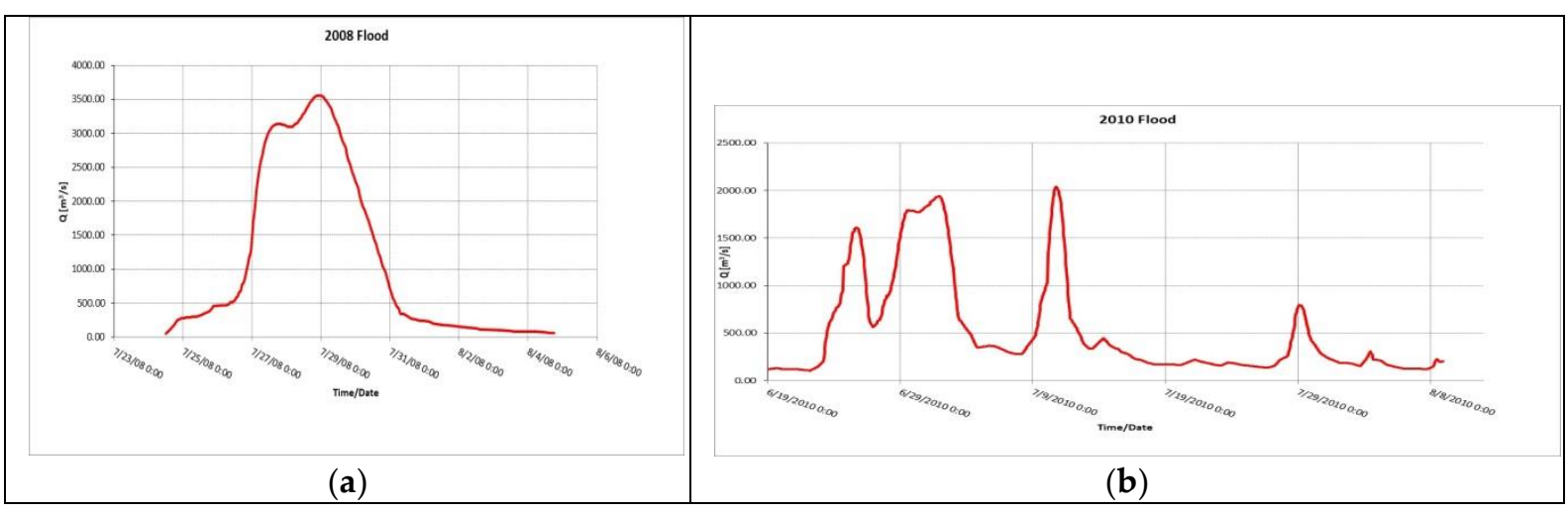

Figure 18. Remarkable floods registered in 2008 and 2010: (a) 2008 flood; (b) 2010 flood

The most difficult situation in operation occurred in 2008, when the spillways were used at maximum discharge capacity to avoid crest overflow (Figure 19a). Water level in the reservoir reached 98.27 m.a.s.1. (Figure 19b) overpassing the upper limit of the flap gates (98.20 m.a.s.1.), which represents the design flood level for medium floods (1\% probabilty of exceedance of the maximum discharge).

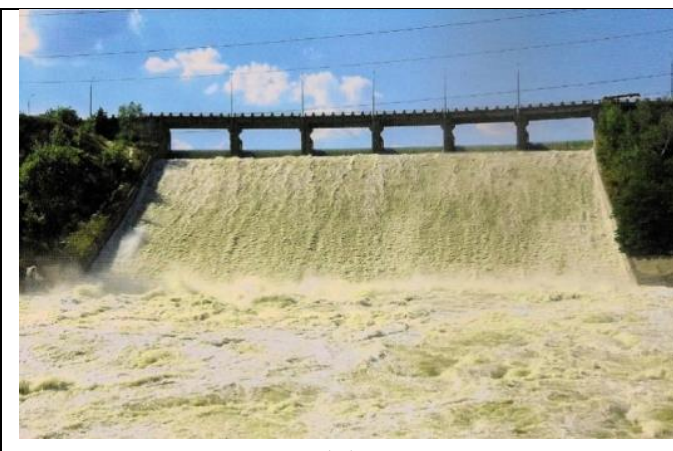

(a)

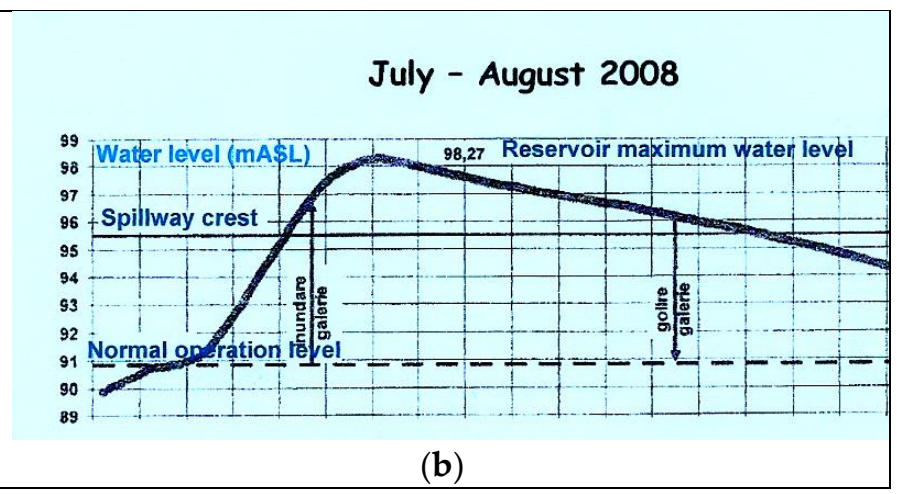

(b)

Figure 19. Stânca-Costești reservoir during 2008 flood (ANAR): (a) downstream view; (b) evolution of water level in the reservoir

Since the reservoir was put into operation in 1978, the flood characteristics modified, being necessary to re-evaluate the maximum discharges and flood volumes and to change accordingly the operation rules of the reservoir during medium and rare floods.

An update in 2007 of the maximum discharges, before the two exceptional floods in 2008 and 2010, provided the following values:

Table 7. Maximum discharges at Rădăuți-Prut 


\begin{tabular}{|c|c|}
\hline Probability of exceedance & Q max $\mathbf{~} \%$ \\
\hline $0.1 \%$ & 4300 \\
\hline $1 \%$ & 2800 \\
\hline $10 \%$ & 1500 \\
\hline
\end{tabular}

A classical statistical analysis of the maximum discharges for the period 1987-2016 based on BM approach is presented in the following figures: LogNormal distribution with 3 and 2 parameters (Figure 20) and a POT approach using Pearson 3 distribution (Figure 21).

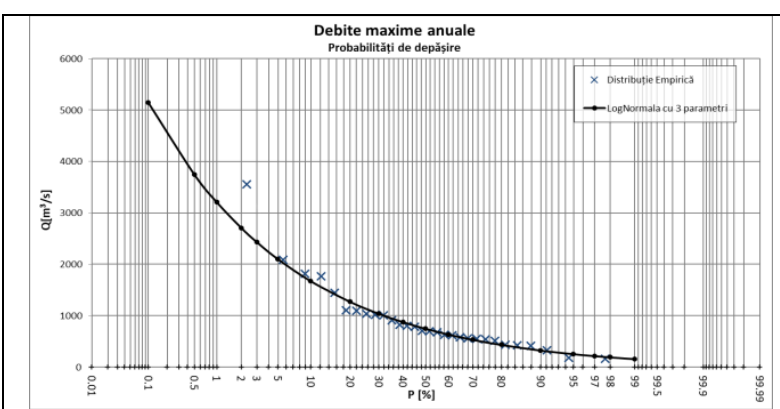

(a)

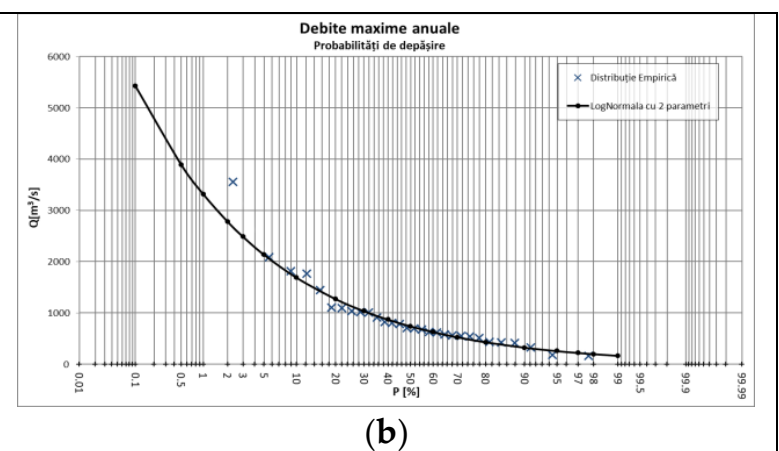

(b)

Figure 20. Annual maximum discharges fitted with Lognormal distribution: (a) LN3; (b) LN2

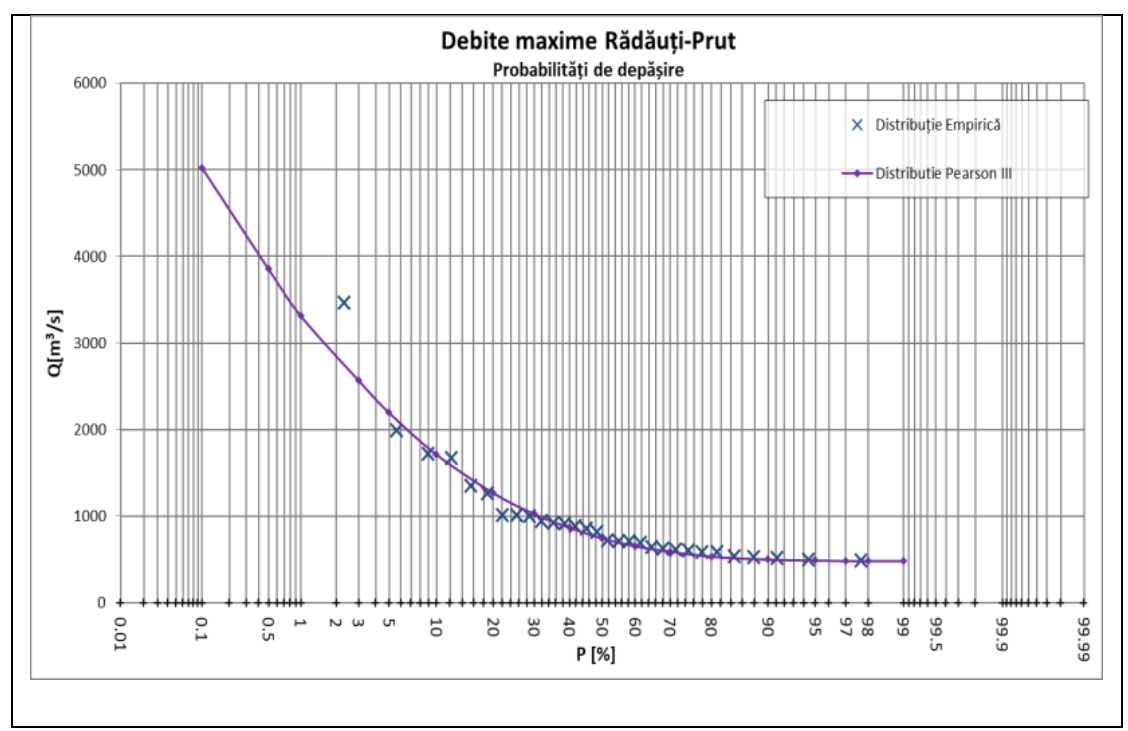

Figure 21. Maximum discharges (POT approach) - Pearson 3 distribution

Table 8. Re-evaluation of maximum discharges at Rădăuți-Prut

\begin{tabular}{|c|c|c|c|}
\hline P\% & LogN 3p (BM) & LogN 2p (BM) & Pearson 3 (POT) \\
\hline 0.1 & 5143 & 5425 & 5110 \\
\hline 1 & 3203 & 3311 & 3400 \\
\hline 10 & 1670 & 1686 & 1800 \\
\hline
\end{tabular}


Compared with 2007 evaluation, one can notice an increase of Qp\% discharges of about 16\% for $0.01 \%$ AEP and $12.5 \%$ for $1 \%$ AEP.

Using the presented methodology, the floods above the threshold 2 (which was set to $90 \mathrm{~m} 3 / \mathrm{s}$, almost the average multiannual flow) were normalised and then grouped into classes of similar shapes (Figure 22). In some classes only a flood with a very particular shape is represented (classes 6; $8 ; 9$ and 10$)$, while in other classes $(1 ; 2 ; 3 ; 4 ; 5$ and 7) more floods are grouped.

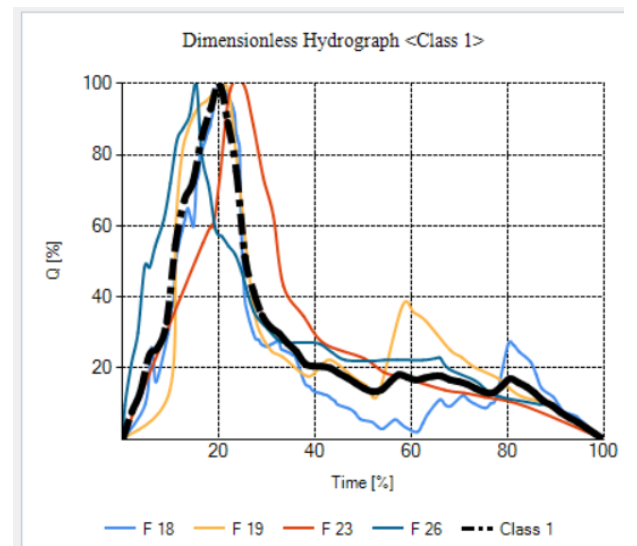

(a)

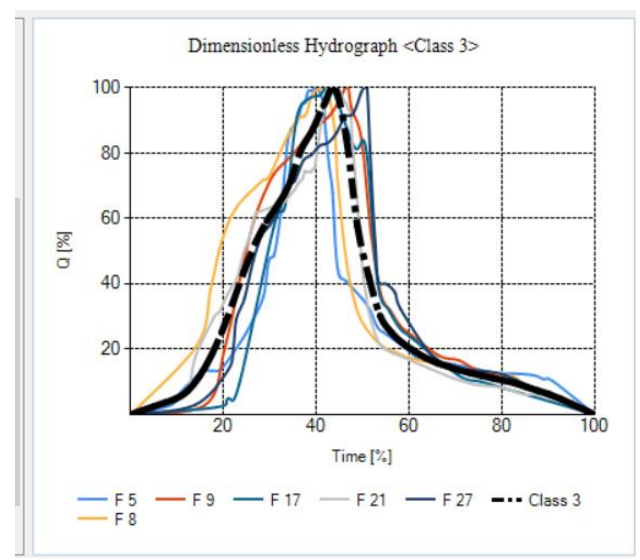

(c)

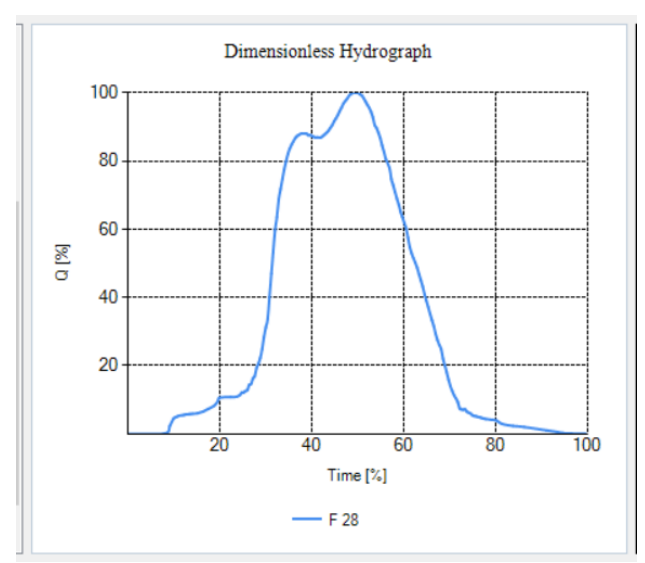

(e)

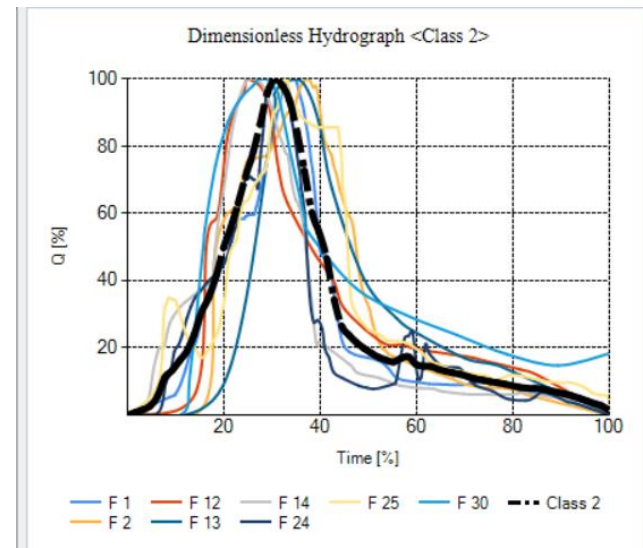

(b)

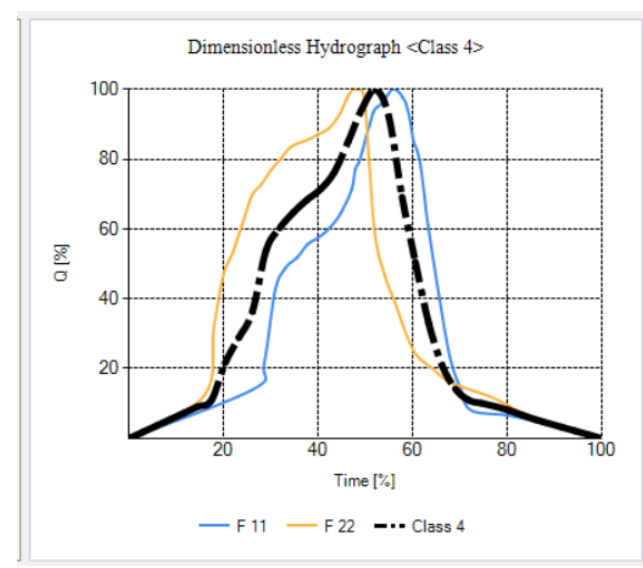

(d)

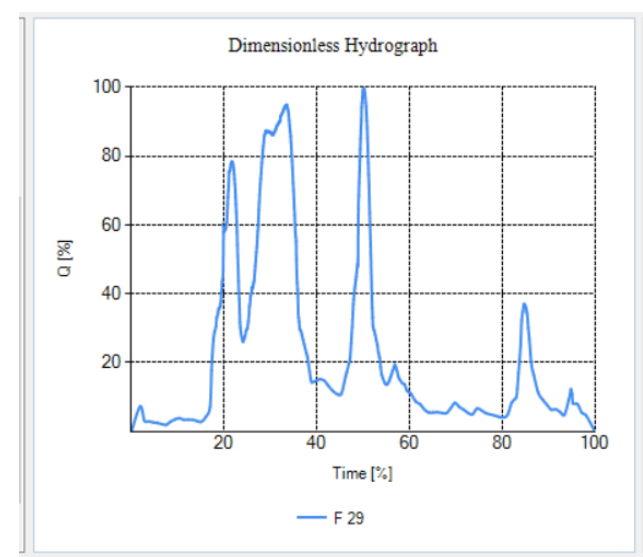

(f)

Figure 22. Classes of dimensionless floods: (a) Class 1; (b) Class 2; (c) Class 3; (d) Class 4; (e) Class 9; (f) Class 10 
The statistical processing of the maximum discharges (BM and OT approach) and floods volume above the threshold are presented in Figure 23. Based on these results (Tables 9-11), the design floods were derived. Only the design floods for classes 9 and 10 are presented in the following, due to the exceptional character of these floods. The flood in class no. 9 reproduces the shape of 2008 flood, which was very compact and raised a difficult situation for flood attenuation, while the flood in class no. 10 has a similar shape with 2010 flood, characterized by 3 peaks, an exceptional duration and a huge volume.

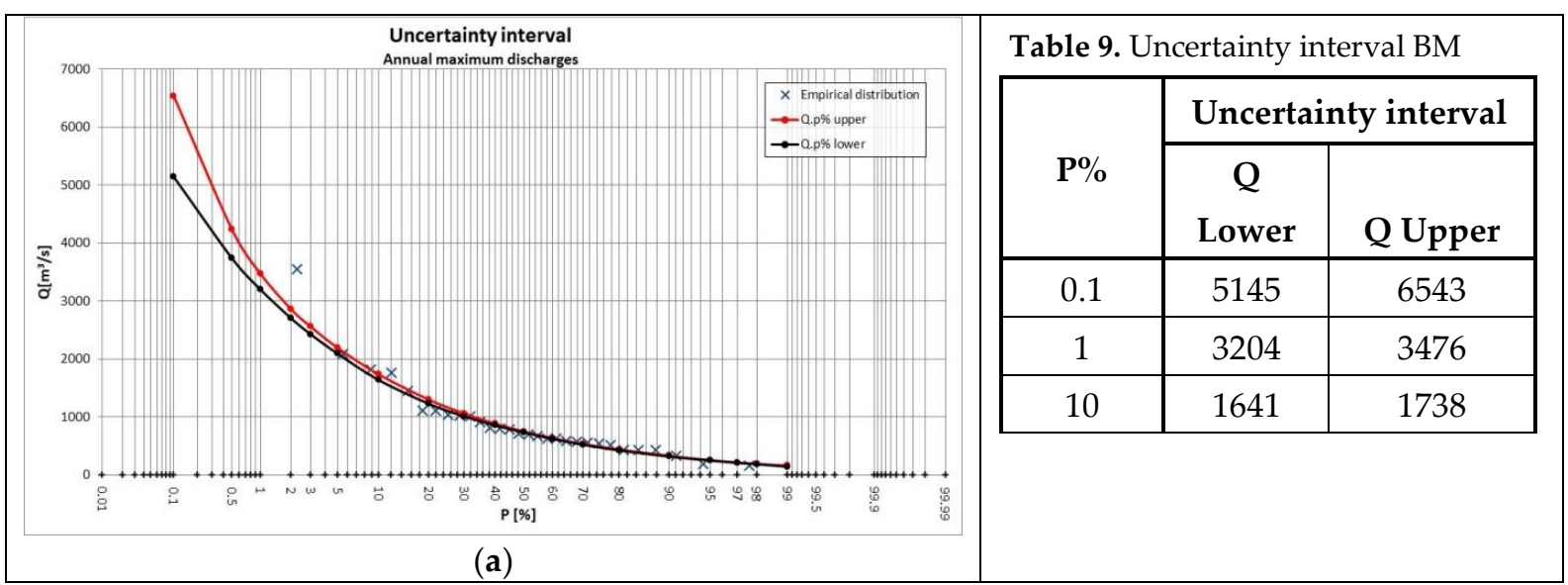

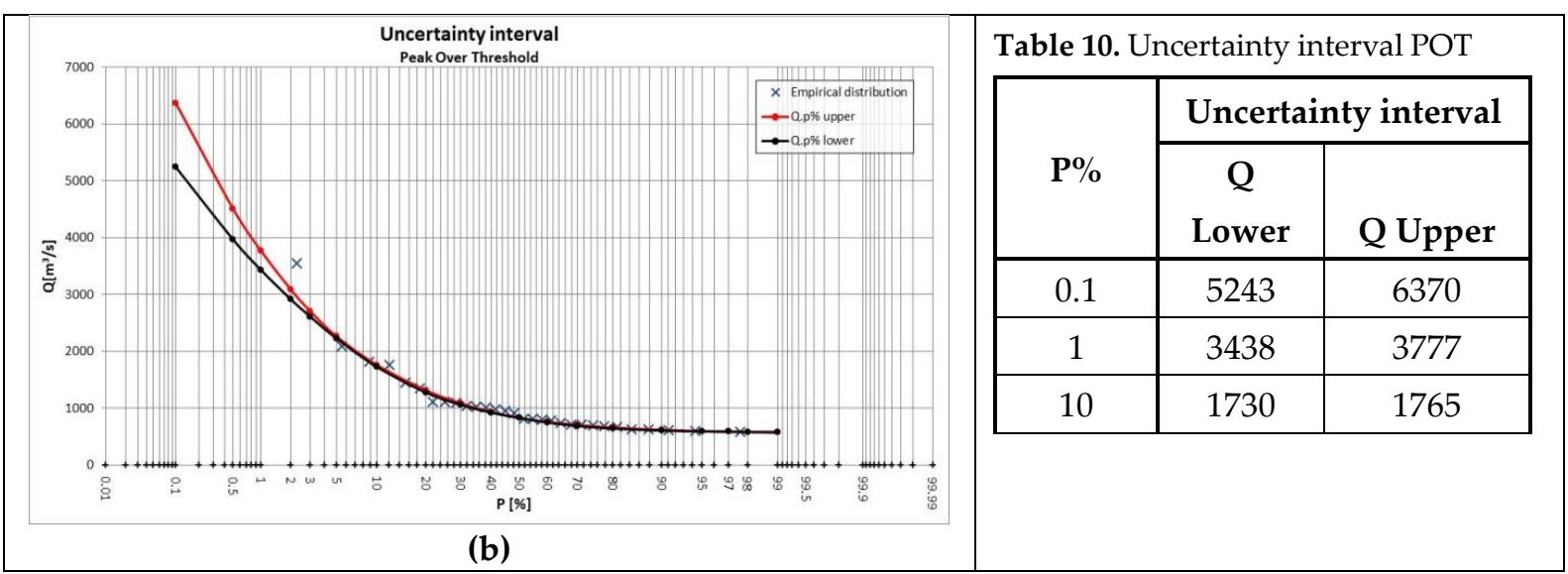

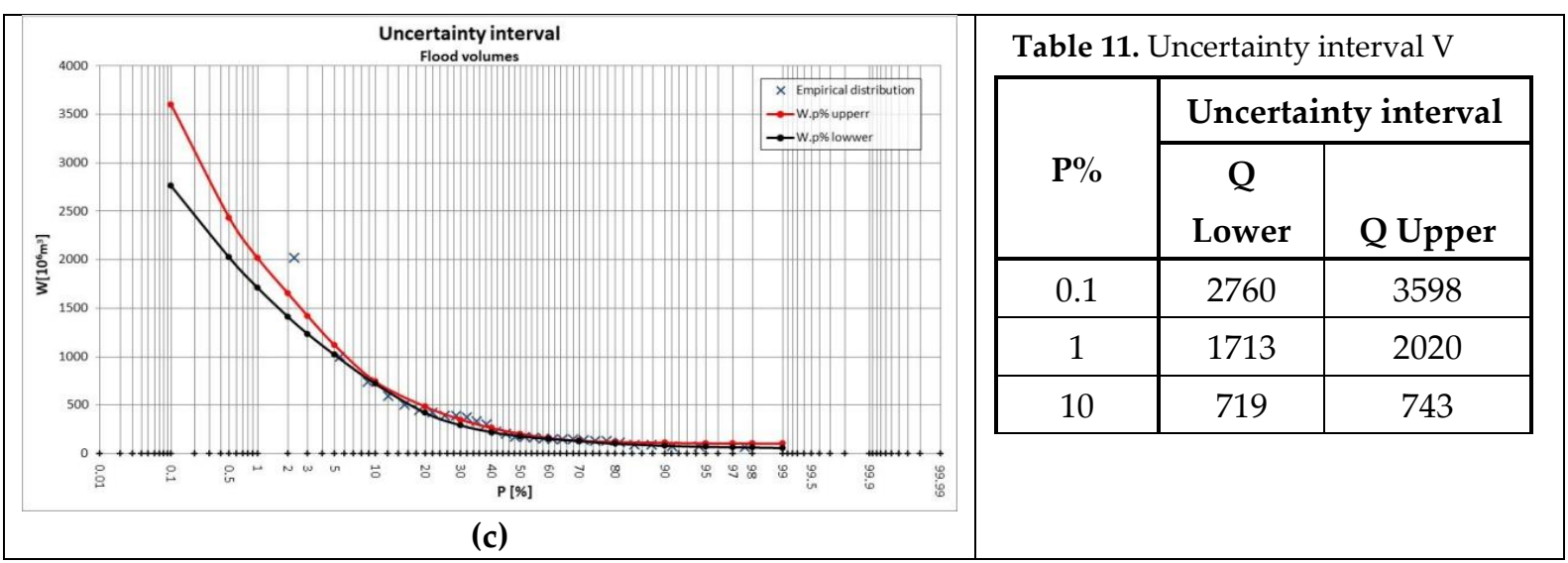

Figure 23. Statistical processing of maximum discharges and floods volume: (a) BM; (b) POT; (c) V

The design floods for classes 9 and 10 have the following characteristics (Table 12):

Table 12. Parameters of the design floods at Rădăuți-Prut 


\begin{tabular}{|c|c|c|c|c|c|c|c|}
\hline \multirow[t]{2}{*}{$\mathbf{P} \%$} & \multirow{2}{*}{$\begin{array}{c}\text { Flood } \\
\text { characterization }\end{array}$} & \multirow{2}{*}{$\begin{array}{l}Q \max \\
\left(\mathrm{m}^{3} / \mathrm{s}\right)\end{array}$} & \multirow{2}{*}{$\begin{array}{c}W \\
\left(10^{6} \mathrm{~m}^{3}\right)\end{array}$} & \multicolumn{2}{|c|}{ Class 9} & \multicolumn{2}{|c|}{ Class 10} \\
\hline & & & & $\begin{array}{c}\mathrm{Tp} \\
\text { (days) }\end{array}$ & Tt (days) & $\begin{array}{c}\text { Tp } \\
\text { (days) }\end{array}$ & Tt (days) \\
\hline \multirow[t]{2}{*}{$0.1 \%$} & MDF & 6543 & 2760 & 7.5 & 15.4 & 11.2 & 22.4 \\
\hline & MVF & 5145 & 3598 & 12.5 & 25.6 & 18.7 & 37.3 \\
\hline \multirow[t]{2}{*}{$1 \%$} & MDF & 3476 & 1713 & 8.9 & 18.2 & 13.3 & 26.5 \\
\hline & MVF & 3204 & 2020 & 11.4 & 23.3 & 17.0 & 34.0 \\
\hline \multirow[t]{2}{*}{$10 \%$} & MDF & 1738 & 719 & 7.7 & 15.7 & 11.4 & 22.8 \\
\hline & MVF & 1641 & 743 & 8.4 & 17.2 & 12.5 & 25.0 \\
\hline
\end{tabular}

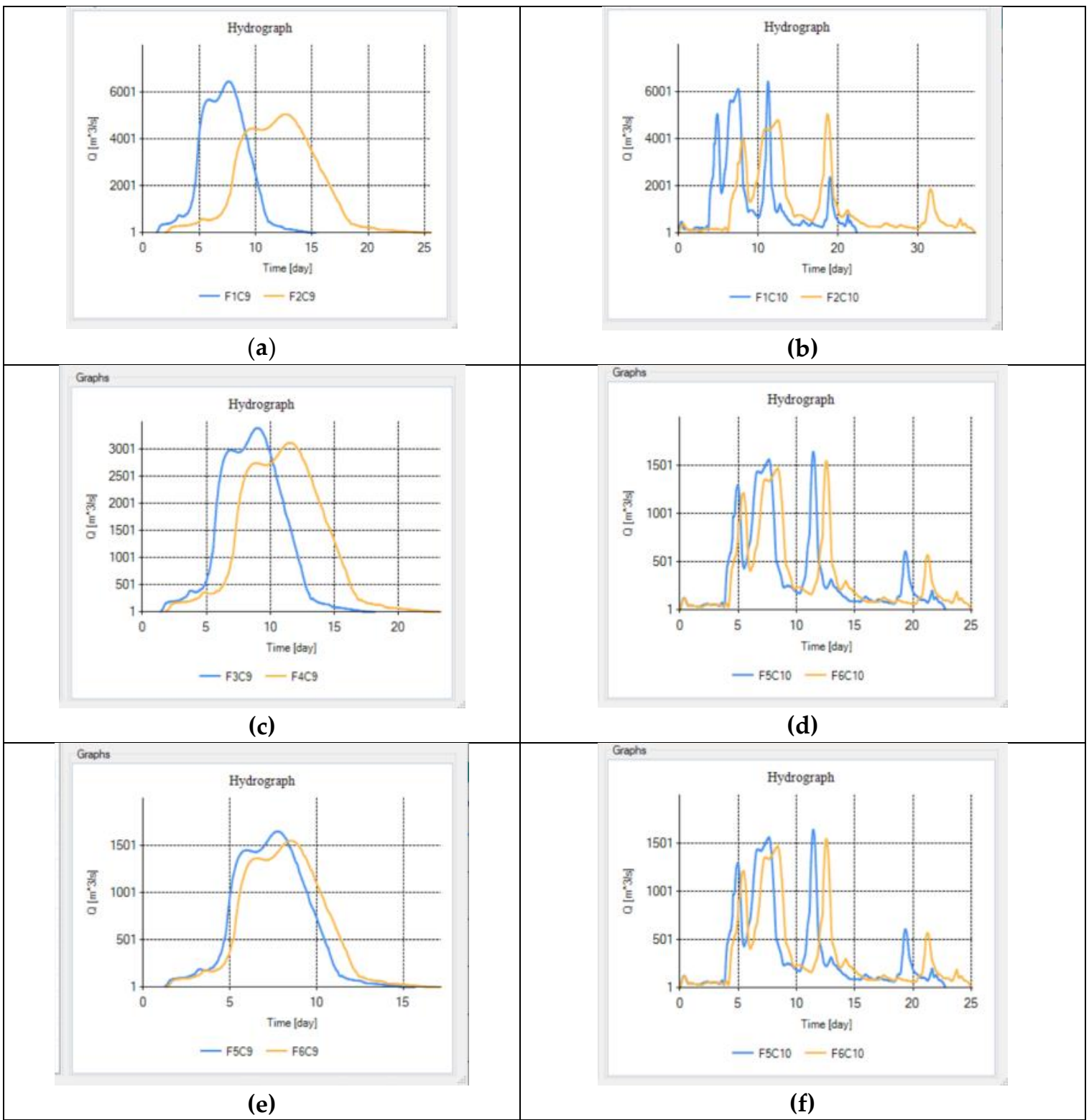

Legend: MDF - blue solid line; MVF - orange solid line

Figure 24. Maximum discharge flood and maximum volume flood: (a) and (b) $Q \quad 0.1 \%$; (c) and (d) Q 1\%; (e) and (f) Q 10\%. (a), (c), (e) Class 9. (b), (d), (f) Class 10. 
In the Figure 24, the maximum discharge flood and maximum volume flood of the classes 9 and 10 for the probabilities of exceedance $0.1 \% ; 1 \%$ and $10 \%$ are shown. The design floods in the class 9 and 10, for the same type (MDF or MVF) differ only by time to peak and the total duration, while the maximum discharge and volume respectively are the same.

It can be seen that the differences between the maximum discharge flood MDF and maximum volume flood MVF diminish as the probability of exceedance increases.

In the Figure 25, the maximum discharge floods $0.1 \%, 1 \%$ and $10 \%$ are represented on the same graph for class 9 and class 10 respectively.

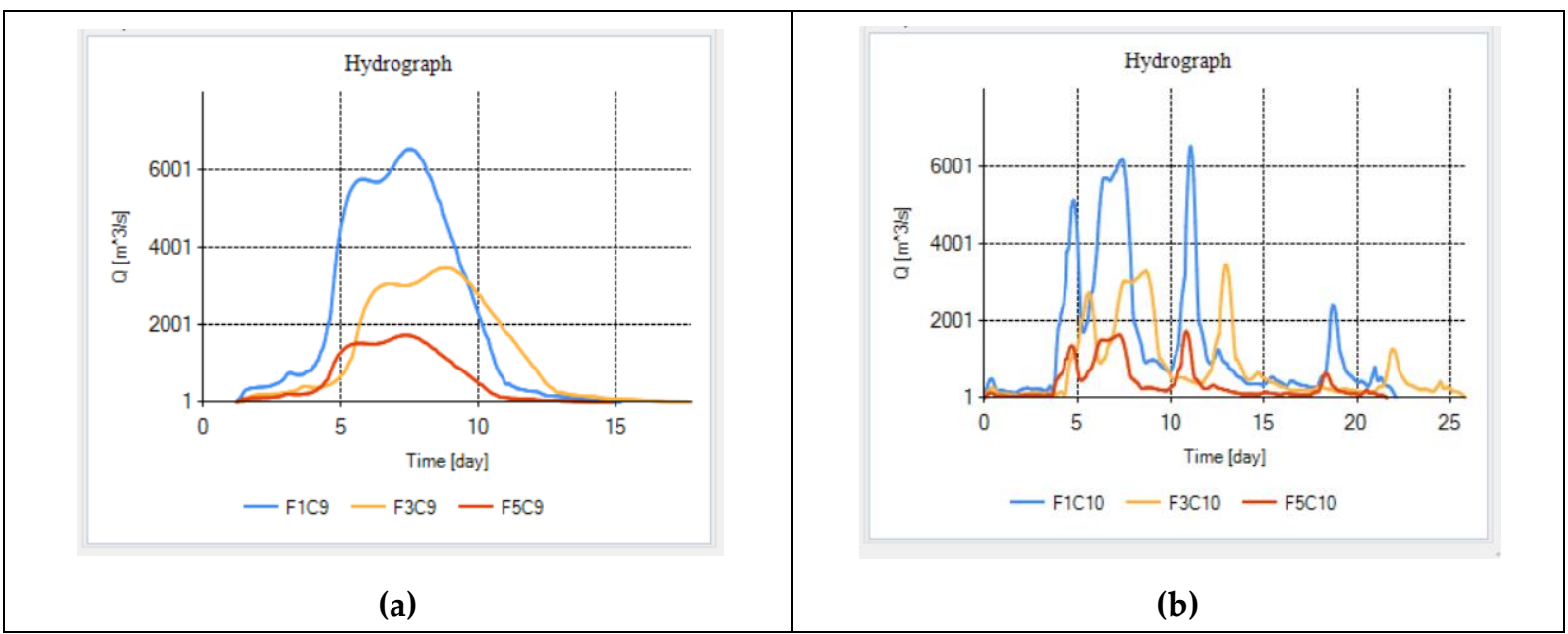

Figure 25. Maximum discharge flood for $0.1 \%$ (blue); $1 \%$ (orange) and $10 \%$ (red).

(a) Class 9; (b) Class 10.

\section{Discussion}

1. The limits of the uncertainty interval can be established in different ways:

- Choosing the best distribution based on statistical tests and using the confidence interval to define the lower and the upper limits of the maximum discharges and flood volumes respectively. The statistical distribution can be different for maximum discharges and for flood volumes. Usually, the confidence level $\beta$ is $95 \%$, but it can be reduced to avoid a large difference between the upper and lower limit, which normally should be less than $20 \%$.

- Selecting a large number of statistical distributions as largely presented in the previous chapters.

- Establishing a correlation between the maximum discharges and flood volumes and defining the confidence intervals both for discharges and volumes based on the Student distribution.

- Based on bivariate flood frequency analysis.

No matter what approach is used, the main idea is the same: to define upper and lower limits of the uncertainty intervals and to make the appropriate combinations corresponding to the maximum discharge flood characterized by the pair $\left(Q_{U}^{\max }, V_{L}\right)_{P \%}$, respectively to the maximum volume flood $\left(Q_{L}^{\max }, V_{U}\right)_{P \%}$.

2. The maximum discharge flood is necessary for the design of the surface spillways when the top level of the conservation pool coincides with the spillway crest level and the design of the dike's height. The maximum volume flood is used to establish the flood protection volume both under the spillway crest level and above it in order to define the top of the surcharge pool. Both MDF and MVF 
should be used to derive the optimal operation rules of the reservoirs during medium and rare floods. At the same time, both types of floods should be used for determining the position of the infiltration curve through dikes and for stability computation during flood periods: the MDF has a lower duration than the MVF, but the maximum discharges are higher which can lead to a potentially dangerous situation. At the same time the MVF, even if the maximum discharges are lower than in the case of MVF, because of its large duration can also put the dike stability into danger. Finally, both types of floods can be used for deriving the uncertainty related to the delineation of the flooded areas.

3. The floods are grouped into classes based on a similar shape of the dimensionless floods. A large number of such classes can be defined (up to 10-15, depending on the length of the period with available data). The simulations of the reservoirs operation considering different classes of floods of the same probability of exceedance put, however, into evidence that the most critical situations are related to the operation of the outlets during the maximum volume flood having the shape of the registered maximum volume flood (which is very compact and has a large duration) and during the maximum discharge flood (which has a shorter duration, but the gradient of incoming volumes into reservoir is higher than in previous case, meaning a large volume of water should be evacuated in a shorter time in order to avoid reaching dangerous level in the reservoir).

4. The hydrological processing is not an end in itself, but has the role of providing information necessary for the flood management in critical situations, and the obtained results must be realistic from a physical point of view. As such, the selection of the most dangerous situations needs expert judgement, since not always any discharge-volume combination is plausible. For example, the maximum volume flood, Class 1 , for $0.1 \%$ probability of exceedance at Turnu-Măgurele station has a total duration over the threshold $Q_{t h r 2}=8300 \mathrm{~m} 3 / \mathrm{s}$ of about 240 days (8 months), which seems unrealistic (Figure 26a). On the contrary, both floods MDF and MVF, Class 2, for 0.1\% probability of exceedance are realistic (Figure 26b). Even the duration is plausible taking into account that 1970 flood's duration, which has the largest volume registered in 78 years, was 157 days.

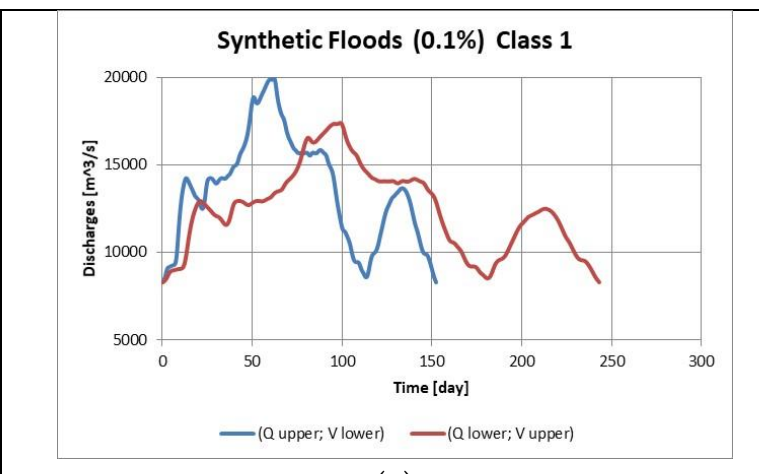

(a)

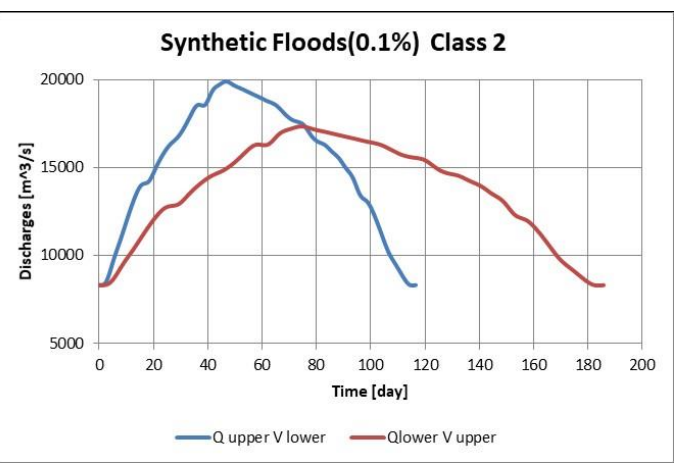

(b)

Figure 26. Design Floods (Q upper; V lower) and (Q lower, V upper): (a) Class 1; (b) Class 2.

5. The design floods that reproduce the shape of registered floods are more credible than the analytic floods that pass through the characteristic points (Figure 1), respecting the volume or the compactness coefficient. If the flood that reproduces the shape of the registered floods in classes 9 and 10 at Rădăuți-Prut station overlaps on the same graph with the analytic flood characterized by the same maximum discharge, volume, time to peak and duration, it is found that there is a fairly 
good agreement in the case of unimodal floods (Figure 27), but very important differences occur for multimodal floods (Figure 28).

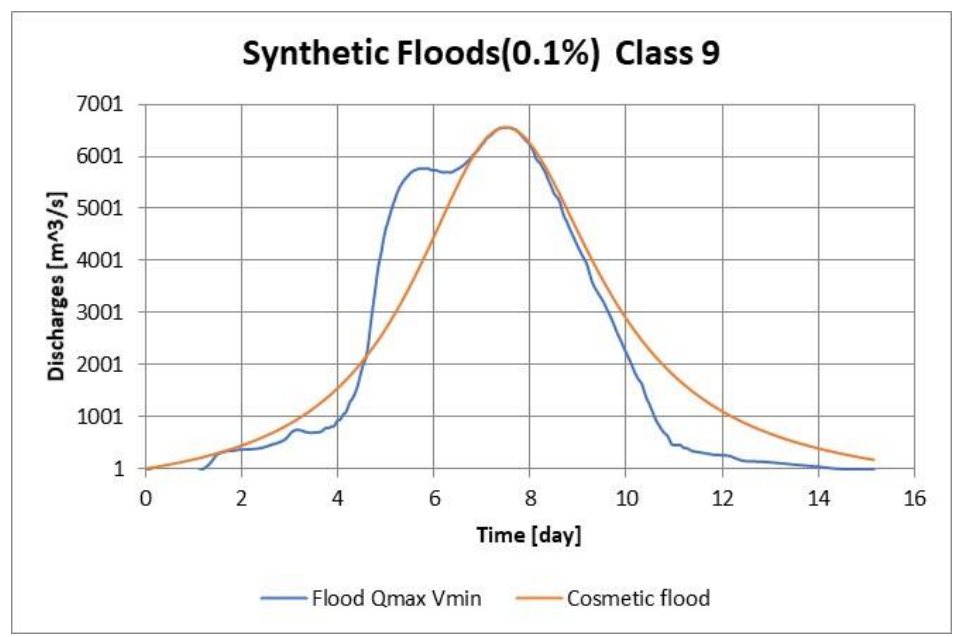

Figure 27. Overlapping unimodal synthetic floods

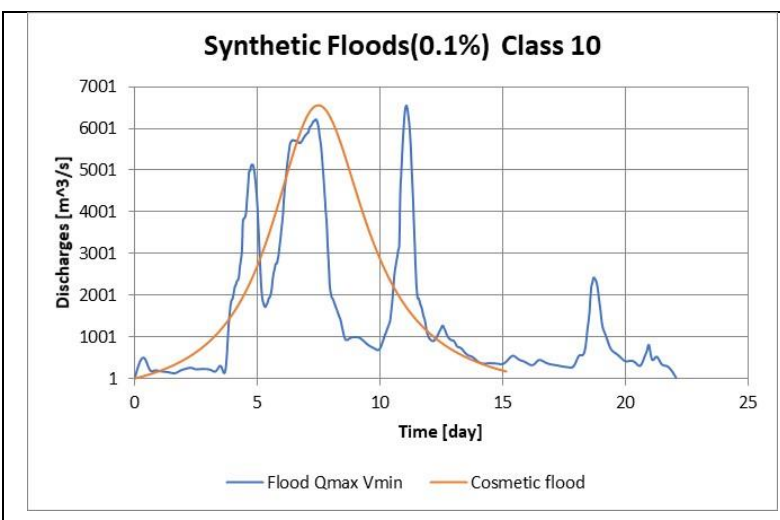

(a)

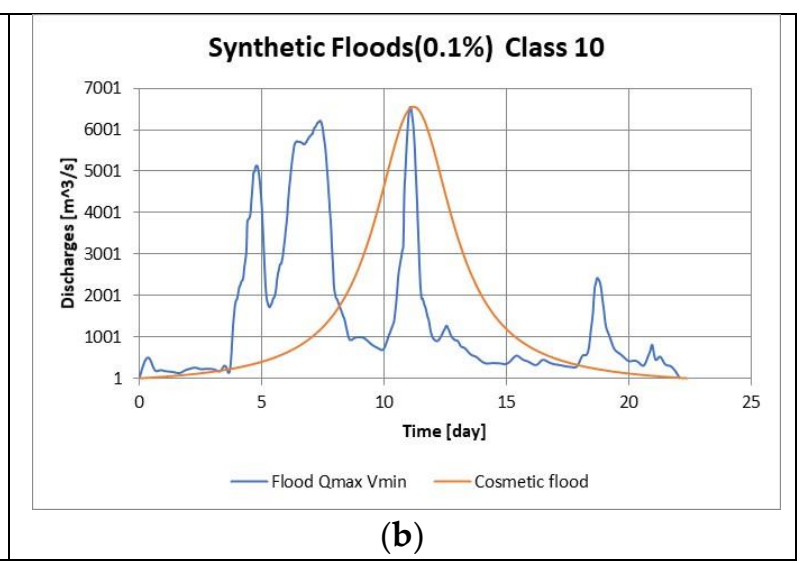

(b)

Figure 28. Overlapping multimodal synthetic floods: (a) the $1^{\text {st }}$ peak; (b) the $2^{\text {nd }}$ peak.

If the purpose is to delineate the flooding areas, then the analytic floods will lead to approximately the same results as the floods reflecting the shape of the registered floods. However, if the purpose is to determine the operational framework rules for the optimal attenuation in a reservoir during flood conditions, it is preferable to use the shape of real floods.

\section{Conclusions}

The hydrological processing of flood waves can be performed at different degrees of complexity, depending on the future utilization of the results. The simplest way, used in case of delineation of the flooded areas or for dikes designing, based on a steady state simulation, is to consider the maximum discharge corresponding to a probability of exceedance $\mathrm{P} \%$, which is treated in the following as a deterministic value, neglecting the associated aleatory and epistemic uncertainty. In such a case, for each probability of exceedance a unique extension of the flooded area is obtained.

If the hydrologic uncertainty is taken into account, for any distribution a confidence interval can be defined. The maximum discharges belong to this interval with a confidence level $\beta$. Considering the upper and lower limits of the discharges, the uncertainty limits of the flooded areas are derived. 
The problem gains in complexity when more distributions are used to fit the registered discharges. All of them approximate well the frequent values of the maximum discharges, but have a very large spread for medium or rare probabilities of exceedance. This scattering defines a range of uncertainty for the extrapolation of maximum discharges outside the measured values. The choice of the upper $(\mathrm{U})$ and the lower (L) limits of this interval is a problem of expert judgement, but normally, the difference between the minimum and maximum values for $0.1 \%$ probability of exceedance should not exceed $20 \%$. Based on the extreme values of the uncertainty interval, the maximum discharge flood $\left(Q_{U}^{\max }, V_{L}\right)_{P \%}$ and the maximum volume flood $\left(Q_{L}^{\max }, V_{U}\right)_{P \%}$ are defined for each probability of exceedance $P \%$. This approach is in perfect agreement with the bivariate analysis, the contour lines for a certain probability of exceedance putting into evidence an infinity of couples (maximum discharge, flood volume), which are not independent variables. From these couples, only the most critical combinations are selected, leading to MDF and MVF.

Apart from these parameters the shape of the design flood, characterized by the time to peak and the total duration, is also important. The easiest way is to use an analytical curve that passes through the characteristic points of the flood. Other possibility, which was largely developed in this paper, is to obtain dimensionless floods, then to define clusters of floods with similar shapes and finally to obtain an average dimensionless flood for each class. Based on them, design floods corresponding to different classes of clusterization, but characterized by the same parameters for each probability of exceedance, are derived.

More than one design flood has also been addressed by other researchers. Quite recently, Mediero et al [3] obtained a set of synthetic hydrographs that preserved the statistical characteristics of the observed peaks, while Volpi and Fiori [16] adopted an ensemble approach choosing the most critical events in term of hydrological loads on the hydraulic structures.

All design floods can be used to examine the consequences of their occurrence upon the environment and hydrotechnical works. However, in a simplified approach only the MDF reproducing the shape of the registered flood characterized by the maximum discharge and the MVF having a similar shape to the flood with the maximum registered volume can be used for further simulations.

The floods corresponding to the maximum discharges will be used for the design of spillways, or for the dike design in order to prevent high levels leading to dike overtopping. The most dangerous floods for reservoirs operation are those that are very compact, corresponding to the maximum compactness coefficient. In these cases, pre-emptying the reservoir based on a reliable hydrological forecast in order to increase the flood protection volume is a necessary management strategy.

For the dike stability, both the MDF and MVF can be used. The MDF, although the high levels have a short duration, can activate preferential routes of infiltration through the galleries of rodents, endangering the stability of the dike. On the other hand, the long duration of MVF floods also makes them dangerous because the infiltration curve can reach the downstream face of the dike. Both floods represent boundary conditions for transient computation of the water flow through the dike and its foundation. The critical gradients will then be computed, putting into evidence the sensitive parts of these hydraulic structures.

In the frame of this paper, 2 case studies were presented : a) processing Turnu-Măgurele daily discharges on Danube River for deriving the MDF and MVF with the purpose to study the stability of the dikes, the flood attenuation in lateral enclosures and the delineation of the flooded areas in 
case of dike break; b) processing Rădăuți-Prut daily discharges on Prut River to obtain floods of different shapes and to study their influence on the optimal operation rules of the spillways and bottom gates of Stânca-Costești reservoir.

Author Contributions: Conceptualization, R.D. and A.F.D.; methodology, R.D. and A.F.D.; software, A.F.D., D.C. and R.T.; validation, R.D., A.F.D., D.C. and R.T.; formal analysis, D.C., R.T.; investigation, R.D. and A.F.D.; data curation, A.F.D.; writing - original draft preparation, R.D.; writing - review and editing, R.D., A.F.D., D.C. and R.T.; visualization, A.F.D.; supervision, R.D.; project administration, R.D.; funding acquisition, R.D. All authors have read and agreed to the published version of the manuscript.

Funding: The elaboration of the Methodology was financed by the Romanian Government through the Ministry of Regional Development within the contract: Establishing the maximum flows and volumes for the calculation of the hydrotechnical retention constructions. Revision of STAS 4068-1 / 82 and 4068-1.2 / 87. Subsequently, it was applied within the European funded projects Danube Floodrisk and EastEvert.

Acknowledgments: The authors are grateful to the National Institute of Hydrology and Water Management, Bucharest, Romania, for providing the data necessary for the study.

Conflicts of Interest: The authors declare no conflict of interest. The funders had no role in the design of the study; in the collection, analyses, or interpretation of data; in the writing of the manuscript, or in the decision to publish the results".

\section{References}

1. Lo, S., 1992. Glossary of Hydrology. Water Resources Publications.

2. Xiao, Y., Guo, S., Liu, P., Yan, B., Chen, L., 2009. Design flood hydrograph based on multicharacteristic synthesis index method, J. Hydrol. Eng., 14(12), 1359-1364.

3. Mediero, L., Jimenez-Alvarez, A., Garrote, L., 2010. Design flood hydrographs from the relationship between flood peak and volume, Hydrol. Earth Syst. Sci., 14, 2495- 2505.

4. Directive 2007/60/EC of the European Parliament and of the Council of 23 October 2007 on the assessment and management of flood risks.

5. Stedinger J.R., Vogel, R.M., Foufoula-Georgiou, E., 1993. Frequency Analysis of Extreme Events. McGraw-Hill, New York, USA.

6. Beven K.J., 2000. Rainfall-Runoff Modelling: The Primer. John Wiley and Sons, Chichester.

7. Smithers, J.C., 2012. Methods for design flood estimation in South Africa, 2012, African Journals Online, Water, SA., Vol. 38 No. 4, pages 633-646, ISSN:0378-4738, DOI: 10.4314/wsa.v38i4.19

8. Yevjevich, V., 1972. Probability and Statistics in Hydrology. Water Resources Publications. Colorado, USA

9. Kitte, G.W., 1977. Frequency and risk analysis in hydrology. Water Resources Publications. Fort Collins, Colorado

10. Bobée, B., Ashkar, F., 1991. The Gamma family and derived distributions applied in Hydrology. Water Resources Publications. Colorado, USA

11. Rosbjerg, D., 2013. Prediction of floods in ungauged basins, in Runoff Prediction in Ungauged Basins. A Synthesis Across Processes, Places and Scales, edited by G. Blöschl, M. Sivapalan, T. Wagener, A. Viglione, and H. Savenije., chap. 9, pp. 189-226, Cambridge Univ. Press, Cambridge, U. K. https://doi.org/10.1002/2014EO020025

12. Gaur, A., Gaur, A., Simonovic, S., 2018. Future changes in Flood Hazard s across Canada under a Changing Climate. Water, 2018, 10, 1441

13. Liu, D.F., Xie, B.T., Li, H.J., 2011. Design Flood Volume of the Three Gorges Dam Project, Publisher: ASCE, Journal of Hydrologic Engineering, 01, Volume 16, Issue 1, pages 71-80, DOI: 10.1061/(ASCE)HE.1943-5584.0000287

14. Favre, A.-C., El Adlouni, S., Perreault, L., Thiémonge, N., Bobée B., 2004. Multivariate hydrological frequency analysis using copulas, Water Resour. Res., 40, W01101, doi:10.1029/2003WR002456.

15. De Michele, C., Salvadori, G., Canossi, M., Petaccia, A., Rosso, R., 2005. Bivariate statistical approach to check adequacy of dam spillway, Journal of Hydrologic Engineering, 10 (1), 50-57. doi:10.1061/(ASCE)1084-0699(2005)10:1(50). 
16. Volpi, E., Fiori, A., 2012. Design event selection in bivariate hydrological frequency analysis, Hydrological Sciences Journal, 57(8), 1506-1515, DOI: 10.1080/02626667.2012.726357

17. Brunner, M. I., Seibert, J., Favre, A.-C., 2016. Bivariate return periods and their importance for flood peak and volume estimation, Wire's Water, 3, 819-833, doi:10.1002/wat2.1173

18. Gaal, L., Szolgay, J., Bacigal, T., Kohnova, S., Hlavcova, K., Vyleta, R., Parajka, J., Bloschl, G., 2016. Similarity of empirical copulas of flood peak-volume relationships; a regional case study of North-West Austria. Contributions to Geophysiscs and Geodesy, vol. 46, issue 3, p. 155-178.

19. Stojkovic, M., Prohaska, S., Zlatanovic, N. , 2017. Estimation of flood frequencies from data sets with outliers using mixed distribution functions. Journal of Applied Statistics, vol.44, issue 11, p, 2017-2035.

20. Kang, L., Jiang, S., Hu, X., Li, C., 2019. Evaluation of Return Period and Risk in Bivariate Non-Stationary Flood Frequency Analysis. Water, 11(1), 79; https://doi.org/10.3390/w11010079

21. Brunner, M.I., Sikorska-Senoner, A.E, 2019. Dependence of flood peaks and volumes in modelled discharge time series: Effect of different uncertainty sources. Journal of Hydrology, vol. 572, 620-629

22. Prohaska, S., Ilić, A., 2019. Ch. 8. Theoretical Design Hydrographs at the Hydrological Gauging Stations along the Danube River. In: Pekárová, P., Miklánek, P. (ed): Flood regime of rivers in the Danube River basin. IH SAS, CD ROM, Bratislava, 215 pp. +450 pp.

23. Yue, S., Rasmussen, P., 2002. Bivariate frequency analysis: Discussion of some useful concepts in hydrological applications, Hydrol. Processes,16, 2881 - 2898

24. Salvadori, G., De Michele, C., 2004. Frequency analysis via copulas: theoretical aspects and applications to hydrological events. Water Resources Research, 40, W12511, doi:10.1029/2004WR003133.

25. Chuntian, C., Chau, K.W., Chunping, O., 2001. Flood Control Management System for Reservoirs as Non-structural Measures. International Workshop on Non-structural Measures for Water Management Problems, London, Canada, October 2001, pages 109-120

26. Grimaldi, S., Serinaldi, F., 2006. Asymmetric copula in multivariate flood frequency analysis. Advances in Water Resources. Vol. 29, issue 8, pages 1155-1167

27. Karmakar S, Simonovic S.P., 2008. Bivariate flood frequency analysis: Part1. Determination of marginals by parametric and nonparametric techniques. Journal of Flood Risk Management, 1:190-200. DOI: 10.1111/j.1753-318X.2008.00022.x.

28. Brunner, M. I., Viviroli, D., Sikorska, A. E., Vannier O., Favre A.-C., Seibert, J., 2017. Flood type specific construction of synthetic design hydrographs, Water Resour. Res., 53,1390-1406, doi:10.1002/2016WR019535

29. Mazzorana ,B., Hubl, J., Fuchs, S., 2009. Improving risk assessment by defining consistent and reliable system scenarios. Nat Hazards Earth Syst Sci 9(1):145-159

30. Mazzorana, B., Comiti, F., Fuchs, S., 2013. A structured approach to enhance flood hazard assessment in mountain streams. Nat Hazards 67:991-1009, DOI 10.1007/s11069-011-9811-y

31. STAS 4068/1-82, 1982. Determination of maximum water discharges and volume of watercourses (in Romanian). Romanian Institute of Standardization

32. Stănescu V.Al., Ungureanu, V., Mătreață, M., 2004. Regional analysis of the annual peak discharges in the Danube catchment. The Danube and its catchment - A hydrological monograph, Follow-up volume No.VII, Regional Cooperation of the Danube Countries, Bucharest.

33. Chow, V.T., 1964. Handbook of Hydrology.McGraw-Hill

34. Chow V.T., Maidment D., Mays L., 1988. Applied Hydrology, McGraw-Hill

35. Naden, P.S., 1992. Analysis and use of peaks-over-threshold data in flood estimation. In: Saul A.J. (eds) Floods and Flood Management. Fluid Mechanics and its Applications, vol 15. Springer, Dordrecht. https://doi-org.am.e-nformation.ro/10.1007/978-94-011-1630-5_10

36. Maidment, D.R., 1993. Handbook of Hydrology. Ch. 18. Frequency analysis of extreme events, McGraw-Hill, 18.12-18.13.

37. Malamoud, B.D., Turcotte, D.L., 2006. The applicability of power-law frequency statistics to floods. Journal of Hydrology 322 (2006) 168-180.

38. Leadbetter, M. R., 1991. On a basis for 'Peaks over Threshold' modeling. Statistics and Probability Letters. 12 (4): 357-362. doi:10.1016/0167-7152(91)90107-3.

39. Bhunya,P.K., Singh, R.D., Berndtsson, R., Panda, S.N., 2012. Flood analysis using generalized logistic models in partial duration series. Journal of Hydrology, 420-421, pages 59-71

40. Ouarda, T.B.M.J., Cunderlik, J.M., St-Hilaire, A., Barbet, M., Bruneau, P., Bobée, B., 2006. Data-based comparison of seasonality-based regional flood frequency methods. Journal of Hydrology 330, 329- 339 
41. Bezak, N., Brilly, M., Šraj, M., 2014. Comparison between the peaks-over-threshold method and the annual maximum method for flood frequency analysis. Hydrological Sciences Journal. Vol. 59, No. 5, 959-977. https://doi.org/10.1080/02626667.2013.831174

42. Razmi, A., Golian, S., Zahmatkesh, Z., 2017. Non-Stationary Frequency Analysis of Extreme Water Level: Application of Annual Maximum Series and Peak-over Threshold Approaches. Water Resour Management 31:2065-2083.

43. Kendall, M.G., 1975. Rank Correlation Methods. Griffin, London.

44. Pettit, A. N., 1979. A non-parametric approach to the changepoint problem. Appl. Stat., 28, 126-135.

45. Ang A. H-S., Tang W. H., 2007. Probability Concepts in Engineering, Emphasis on Application to Civil and Environmental Engineering, John Wiley \& Sons

46. Bobée B., Cavadias G., Ashkar F., Bernier J., Rasmussen P., 1993. Towards a systematic approach to comparing distributions used in flood frequency analysis. Journal of Hydrology, vol. 142, issues 1-4, pp 121-136

47. Koutsoyiannis, D., 2005. Uncertainty, entropy, scaling and hydrological statistics. 1. Marginal distributional properties of hydrological processes and state scaling / Incertitude, entropie, effet d'échelle et propriétés stochastiques hydrologiques. 1. Propriétés distributionnelles marginales des processus hydrologiques et échelle d'état, Hydrological Sciences Journal, 50(3), 381-404

48. El Adlouni S., Bobée, B., Ouarda T.B.M.J., 2008. On the tails of extreme event distributions in hydrology. Journal of Hydrology. vol. 355, issues 1-4, pp 16-33

49. Shanin M., Van Oorschoft H.J.L., De Lange S.J., 1993. Statistical Analysis in Water Resources Engineering. Balkema

50. Bačová-Mitková, V., Onderka, M., 2010. Analysis of extreme hydrological Events on the Danube using the Peak Over Threshold method. Journal of Hydrology and Hydromechanics. Volume 58: Issue 2 DOI: https://doi.org/10.2478/v10098-010-0009-x

51. Pekárová, P., Miklánek, P. (ed), 2019.: Flood regime of rivers in the Danube River basin, the Danube and its tributaries - Hydrological Monograph Follow-up Volume IX. IH SAS, Bratislava, CD ROM, 215 pp. + 450 pp Annexes

52. Merz B., Thieken A.H., 2009. Flood risk curves and uncertainty bounds. Natural Hazards, vol. 51, issue 3, p. 437-458, 2009

53. Kundzewicz, Z. W., Robson A. J., 2004. Change detection in hydrological records-a review of the methodology / Revue méthodologique de la détection de changements dans les chroniques hydrologiques, Hydrological Sciences Journal, 49:1, 7-19, DOI: 10.1623/hysj.49.1.7.53993

54. Hoffman, F.O., Hammonds, J.S., 1994. Propagation of uncertainty in risk assessments: the need to distinguish between uncertainty due to lack of knowledge and uncertainty due to variability. Risk Anal 14(5):707-712

55. Apel, H., Thieken, A. H., Merz, B., Bloschl, G., 2004. Flood risk assessment and associated uncertainty. In: Natural Hazards and Earth System Sciences, 4: 295-308

56. Gericke, O.J., du Plessis, J.A., 2012. Evaluation of the standard design flood method in selected basins in South Africa, SAICE-SAISI, Journal of the South African Institution of Civil Engineering, Volume 54, Issue 2, Pages $2-14$

57. Darch, G.J.C., Jones, P.D., 2012. Design flood flows with climate change: method and limitations, Proceedings of the Institution of Civil Engineers-Water Management, vol. 165, issue 10, pages: 553-565, DOI: 10.1680/wama.12.00024

58. Pekárová, P., Miklánek, P., Bálint, G., Belz, J.U., Biondić, D., Gorbachova,L., Kobold, M., Kupusović, E., Soukalová, E., Prohaska, S., Škoda, P., Stanzel, P., Teodor S., 2019. Ch. 1 Average daily discharge and annual peak discharge series collection. In: Pekárová, P., Miklánek, P. (ed): Flood regime of rivers in the Danube River basin. IH SAS, CD ROM, Bratislava, 215 pp. + 450 pp Annexe

59. Apel, H., Merz, B., Thieken, A.H., 2009. Influence of dike breaches on flood frequency estimation. Computers \& Geosciences 35, 907-923

60. FISRWG - Federal Interagency Stream Restoration Working Group, 1998. Stream corridor restoration: principles, processes and practices. National Technical Information Service, U.S. Department of Commerce, Springfield, VA

61. Lang, M., Ouarda, T.B.M.J., Bobée, B., 1999. Towards operational guidelines for over-threshold modeling. Journal of Hydrology 225, 103-117

62. Bayliss, A.C., 1999. Deriving flood peak data. Flood Estimation Handbook. Vol. 3, p.273-283 
63. Šraj, M., Bezak, N., Brilly, M., 2015. Bivariate flood frequency analysis using the copula function: a case study of the Litija station on the Sava River. Hydrol. Process. 29, 225-238, (2015). DOI: 10.1002/hyp.10145

64. https://environmentalrisks.danube-region.eu/projects/danube-floodrisk/

65. https://keep.eu/projects/15262/The-prevention-and-protecti-EN/

66. IUGG. Contributions to Hydrological Sciences, 2012-2015. Ch. 2.7. Statistical Hydrology, pages 194-195. 